\title{
A Comprehensive Study on Li4si1-xtixo4 Ceramics for Advanced Tritium Breeders
}

\author{
Yichao Gong ( $\nabla$ gongyichao@xaut.edu.cn ) \\ Lin Liu \\ xi'an university of technology \\ Jianqi Qi \\ Sichuan University \\ Mao Yang \\ China Academy of Engineering Physics \\ Junjie Li \\ xi'an university of technology \\ Hailiang Wang \\ Sichuan University \\ Hao Guo \\ Sichuan University \\ Guojun Zhang \\ xi'an university of technology \\ Tiecheng Lu \\ Sichuan University
}

Xi'an University of Technology https://orcid.org/0000-0002-8888-9312

\section{Research Article}

Keywords: Tritium breeders, Li4Si1-xTixO4, Thermal conductivity, lonic conductivity, Thermal cycling

Posted Date: June 10th, 2020

DOI: https://doi.org/10.21203/rs.3.rs-34099/v1

License: @ (i) This work is licensed under a Creative Commons Attribution 4.0 International License.

Read Full License 


\section{A comprehensive study on $\mathrm{Li}_{4} \mathrm{Si}_{1-x} \mathrm{Ti}_{x} \mathrm{O}_{4}$ ceramics for advanced tritium breeders}

Yichao Gong ${ }^{\mathrm{a}^{*}}$, Lin Liu ${ }^{\mathrm{a}}$, Jianqi Qi ${ }^{\mathrm{b}}$, Mao Yang ${ }^{\mathrm{c}}$, Junjie $\mathrm{Li}^{\mathrm{a}}$, Hailiang Wang ${ }^{\mathrm{b}}$, Hao

Guo $^{\mathrm{b}}$, Guojun Zhang ${ }^{\mathrm{a} *}$, Tiecheng Lu ${ }^{\mathrm{b} *}$

${ }^{\text {a }}$ School of Materials Science \& Engineering, Xi'an University of Technology, Xi'an, 710048, China

${ }^{\mathrm{b}}$ College of Physical Science and Technology, Sichuan University, Chengdu, 610064, China

${ }^{\mathrm{c}}$ Institute of Nuclear Physics and Chemistry, China Academy of Engineering Physics, Mianyang, 621900, China

\section{Abstract}

Hetero-elements doped lithium orthosilicate has been considered as advanced tritium breeders due to its superior performances. In this work, $\mathrm{Li}_{4} \mathrm{Si}_{1-x} \mathrm{Ti}_{x} \mathrm{O}_{4}$ ceramics were prepared by proprietary hydrothermal process and multistage sintering. The reaction mechanism of $\mathrm{Li}_{4} \mathrm{Si}_{1-x} \mathrm{Ti}_{x} \mathrm{O}_{4}$ was put forward. XRD and SEM analyses indicate that insertion of Ti leads to lattice expansion, enhances the sinterability and changes the fracture mode. The compressive tests show that the crush load increases almost four times by increasing $x$ from 0 to 0.2 . However, the thermal conductivity and ionic conductivity are the best when $x=0.05$ and $x=0.1$, respectively. Thermal cycling stability of $\mathrm{Li}_{4} \mathrm{Si}_{1-x} \mathrm{Ti}_{x} \mathrm{O}_{4}$ pebbles was further appraised through investigating the changes of microstructure and crush load. After undergoing thermal cycling, the $\mathrm{Li}_{4} \mathrm{Si}_{1-x} \mathrm{Ti}_{x} \mathrm{O}_{4}$ still show higher crush load compared with $\mathrm{Li}_{4} \mathrm{SiO}_{4}$, despite $\mathrm{Ti}$ segregation in some samples. The $x=0.05$ sample exhibits excellent thermal cycling stability. To be sure, Ti doping improves the overall performance of $\mathrm{Li}_{4} \mathrm{SiO}_{4}$.

\footnotetext{
${ }^{*}$ Corresponding authors. Tel.: +86 2982312977.

E-mail addresses: gongyichao@xaut.edu.cn (Y. Gong), zhangguojun@xaut.edu.cn (G. Zhang), lutiecheng@vip.sina.com (T. Lu).
} 
Keywords: Tritium breeders; $\mathrm{Li}_{4} \mathrm{Si}_{1-x} \mathrm{Ti}_{x} \mathrm{O}_{4}$; Thermal conductivity; Ionic conductivity; Thermal cycling

\section{Introduction}

Tritium breeding materials (TBMs) are taken as one of the key functional materials for fusion reactor blanket. Neutrons generated from the reaction between deuterium (D) and tritium (T) can react with $\mathrm{Li}$ element to produce tritium, thus achieving tritium self-sustaining of a D-T fusion reactor [1-3]. With preferable chemical stability, efficient tritium extraction, high temperature resistance and no magnetohydrodynamic effect, lithium-based ceramics have long been recognized as promising TBMs [2, 4-6]. However, the overall performance of conventional lithium ceramics (i.e. $\mathrm{Li}_{4} \mathrm{SiO}_{4}, \mathrm{Li}_{2} \mathrm{TiO}_{3}, \mathrm{Li}_{2} \mathrm{O}, \mathrm{LiAlO}_{2}, \mathrm{Li}_{2} \mathrm{ZrO}_{3}$ etc.) is still difficult to achieve satisfactory results. In order to improve their corresponding performance, diverse advanced TBMs, such as $\mathrm{Li}_{2+x} \mathrm{TiO}_{3+y}$ [7-9], mixed-phase ceramics represented by $\mathrm{Li}_{2} \mathrm{TiO}_{3} / \mathrm{Li}_{4} \mathrm{SiO}_{4}$ [10-13], oxides modified ceramics [14-16] and hetero-element doped ceramics (notably $\mathrm{Li}_{4+x} \mathrm{Si}_{1-x} \mathrm{Al}_{x} \mathrm{O}_{4}$ ) were prepared in recent years [17-20]. And previous studies have shown that $\mathrm{Al}$ doped lithium orthosilicate exhibits the enhanced crushing strength $[17,19,20]$, thermal and ionic conductivity [17, 20-22], and tritium release performance [18].

Since TBMs should endure long periods of harsh operating conditions (high temperature, thermal gradient, irradiation by neutron and energetic particles), thermal and irradiation stability are two important parameters and deserve more attention. However, the influence of doping elements on the thermal cycling stability of TBMs has not been investigated so far. Meanwhile, fine-grained ceramics are identified as the most promising, regarding tritium release behavior and mechanical strength [23]. But with the grain refinement, surface energy of ceramic particles increases, and thus 
the structural and functional instability of materials may get more acute in high temperature environment. Therefore, it is significant to fabricate fine-grained lithium ceramic solid solution and investigate its thermal cycling stability.

The aim of this work is to prepare $\mathrm{Li}_{4} \mathrm{Si}_{1-x} \mathrm{Ti}_{x} \mathrm{O}_{4}$ by proprietary hydrothermal process and multistage sintering ( $\mathrm{Ti}$ has lower neutron activation than $\mathrm{Al}$ ), and to investigate the influences of Ti doping on the microstructure, mechanical and physical properties of $\mathrm{Li}_{4} \mathrm{SiO}_{4}$. Furthermore, the thermal cycling stability of $\mathrm{Li}_{4} \mathrm{Si}_{1-x} \mathrm{Ti}_{x} \mathrm{O}_{4}$ pebbles is further studied. These results can cast light for future development of advanced tritium breeding materials.

\section{Experimental details}

Lithium hydroxide monohydrate, fumed $\mathrm{SiO}_{2}$ (Hydrophilic-300) and $\mathrm{TiO}_{2}(30$ $\mathrm{nm}$, anatase, hydrophilic) were purchased from Aladdin Ltd. (Shanghai, China). All chemicals were used without further purification.

\subsection{Preparation of precursor powders}

The precursor powders were hydrothermally synthesized using lithium hydroxide monohydrate, fumed $\mathrm{SiO}_{2}$ and $\mathrm{TiO}_{2}$ nanopowders with a ratio of 4:1-x:x ( $x=0,0.05$, $0.1,0.2)$. Briefly, lithium hydroxide monohydrate $(0.14 \mathrm{~mol})$ was thoroughly dissolved in $70 \mathrm{ml}$ of deionized water under magnetic stirring. Meanwhile, fumed $\mathrm{SiO}_{2}(0.035(1-x) \mathrm{mol})$ was uniformly dispersed in $70 \mathrm{ml}$ of ethanol. Subsequently, the above two solutions were mixed under magnetic stirring at room temperature. After that, $\mathrm{TiO}_{2}$ nanopowders $(0.035 x \mathrm{~mol})$ were added, and continued stirring for $30 \mathrm{~min}$. Then, the mixed solution was transferred into a Teflon-lined stainless-steel autoclave with a capacity of $200 \mathrm{ml}$ and performed at $180{ }^{\circ} \mathrm{C}$ for $12 \mathrm{~h}$. Finally, hydrothermal products were dried at $80{ }^{\circ} \mathrm{C}$ for overnight, and ground in an agate mortar to obtain precursor powders. 


\subsection{Fabrication of $\mathrm{Li}_{4} \mathrm{Si}_{1-x} \mathrm{Ti}_{x} \mathrm{O}_{4}$ pebbles}

The as-prepared precursor powders and deionized water were mixed in a mass ratio of 5:4 to form the slurry, then the green spheres could be produced by dropping the slurry through a nozzle $(0.7 \mathrm{~mm}$ in diameter $)$ into a container of liquid nitrogen. By freezing for more than $15 \mathrm{~min}$, the green spheres were salvaged and placed on filter papers, dried in air for $30 \mathrm{~min}$ and then in drying oven of $70{ }^{\circ} \mathrm{C}$ for overnight. $\mathrm{Li}_{4} \mathrm{Si}_{1-x} \mathrm{Ti}_{x} \mathrm{O}_{4}$ pebbles could be finally obtained by sintering the dried green spheres in a box-type resistance furnace. To be specific, the samples were heated to $420{ }^{\circ} \mathrm{C}$, dwelling for $1 \mathrm{~h}$, then heated to $720{ }^{\circ} \mathrm{C}$, dwelling for $1 \mathrm{~h}$, finally sintered at $800{ }^{\circ} \mathrm{C}$ for 4 h. The heating rate was $5^{\circ} \mathrm{C} / \mathrm{min}$.

\subsection{Characterization}

Thermal behavior of the precursor powders was studied by thermogravimetry and differential scanning calorimetry (NETZSCH 409 PC) in air at a constant heating rate of $10{ }^{\circ} \mathrm{C} / \mathrm{min}$. The phase composition and crystal structure were investigated by X-ray diffractometry (XRD-7000), and the cell parameters were refined via Jade 6.5 software. The morphology was observed by scanning electron microscope (Model S-4800, Hitachi, Japan), and grain size was measured by Nano Measure 1.2 software from SEM images. The density was measured by an electronic density balance using ethyl alcohol as the immersion medium. The crush load was tested by a universal material strength-testing machine with a $5 \mathrm{kN}$ load cell and cross-head speed of 0.1 $\mathrm{mm} / \mathrm{min}$ (HT-2402). To minimize the influence caused by the pebble size, the pebbles with a diameter of 1.2 1.3 mm were used for the test. The average crush load was estimated based on the results of more than ten pebbles. For thermal and ionic conductivity tests, the precursor powders were pressed into pellets and sintered at the same sintering process. The thermal conductivity was measured by LFA 457 Micro 
Flash Analyzer of NETZSCH. The ionic conductivity was determined by AC impedance spectra measured using an Agilent E4980A impedance analyzer in the frequency range from 100 to $10^{6} \mathrm{~Hz}$, and analyzed by fitting the equivalent circuit model using the ZView software. For thermal cycling tests, the ceramic pebbles were heated to $800{ }^{\circ} \mathrm{C}$ in a box-type resistance furnace, dwelling for $4 \mathrm{~h}$, then cooled down to room temperature (set the heating and cooling rate to $5^{\circ} \mathrm{C} / \mathrm{min}$ ). After each three cycles, a batch of ceramic pebbles were fetched out for microstructure characterization and compressive strength testing.

\section{Results and discussion}

\subsection{Phase composition of precursor powders}

Fig. 1 shows the XRD patterns of the precursor powders synthesized via hydrothermal process. The undoped samples consist of $\mathrm{Li}_{2} \mathrm{SiO}_{3}$ and $\mathrm{Li}_{2} \mathrm{CO}_{3}$, suggesting $\mathrm{LiOH}$ and $\mathrm{SiO}_{2}$ tend to generate stable $\mathrm{Li}_{2} \mathrm{SiO}_{3}$ instead of $\mathrm{Li}_{4} \mathrm{SiO}_{4}$ in the hydrothermal reaction system, and the rest of $\mathrm{Li}^{+}$changes to $\mathrm{Li}_{2} \mathrm{CO}_{3}$ when drying the hydrothermal products. The diffraction peaks of the Ti doped samples are basically the same as that of the undoped one, except the emergence of $\mathrm{Li}_{2} \mathrm{TiO}_{3}$ peaks. Moreover, with the increase of $\mathrm{Ti}$ content, the proportion of $\mathrm{Li}_{2} \mathrm{CO}_{3}$ decreases. It reveals there are two competitive reactions.

$$
\begin{aligned}
& 2 \mathrm{LiOH}+\mathrm{SiO}_{2} \rightarrow \mathrm{Li}_{2} \mathrm{SiO}_{3}+\mathrm{H}_{2} \mathrm{O} \\
& 2 \mathrm{LiOH}+\mathrm{TiO}_{2} \rightarrow \mathrm{Li}_{2} \mathrm{TiO}_{3}+\mathrm{H}_{2} \mathrm{O}
\end{aligned}
$$

\subsection{TD/DSC analyses}

The TG/DSC curves of precursor powders with varying Ti doping amount are illustrated in Fig. 2. Slight weight loss at around $425{ }^{\circ} \mathrm{C}$ in the TG curves can be ascribed to the reaction of residual $\mathrm{SiO}_{2} / \mathrm{TiO}_{2}$ with $\mathrm{Li}_{2} \mathrm{CO}_{3}$ [24]. Major weight loss occurs in the range of $650-750{ }^{\circ} \mathrm{C}$, accompanied by a sharp exothermic peak at $709{ }^{\circ} \mathrm{C}$, 
which is attributed to the formation of $\mathrm{Li}_{4} \mathrm{Si}_{1-x} \mathrm{Ti}_{x} \mathrm{O}_{4}$. The weight loss decreases with increasing $\mathrm{Ti}$ content due to the reduced lithium carbonate in the samples, in accordance with XRD results. Compared with the undoped sample, the exothermic peak of Ti doped samples shifts to lower temperature, indicating Ti doping can reduce the reaction temperature and raise the reaction efficiency. This is due to the lattice distortion caused by the substitution of $\mathrm{Ti}^{4+}$ for $\mathrm{Si}^{4+}$, which may reduce the activation energy [25]. No obvious weight changes are found above $800{ }^{\circ} \mathrm{C}$, suggesting the synthesis process is finished. Moreover, considering the release of $\mathrm{CO}_{2}$ caused by above mentioned two reactions, multistage sintering is adopted to reduce the pores and impurities (i.e. $425^{\circ} \mathrm{C}$ for $1 \mathrm{~h}, 710^{\circ} \mathrm{C}$ for $1 \mathrm{~h}$ and $800{ }^{\circ} \mathrm{C}$ for $4 \mathrm{~h}$ ).

\subsection{Phase composition}

Fig. 3 shows the XRD patterns of the $\mathrm{Li}_{4} \mathrm{Si}_{1-x} \mathrm{Ti}_{x} \mathrm{O}_{4}(x=0,0.05,0.1,0.2)$ samples fabricated via multistage sintering. It can be seen that the undoped sample is composed of $\mathrm{Li}_{4} \mathrm{SiO}_{4}$, with a small amount of $\mathrm{Li}_{2} \mathrm{CO}_{3}$. And for the doped samples, the diffraction peaks belonging to $\mathrm{Li}_{4} \mathrm{SiO}_{4}$ can be obviously observed, and the weak diffraction peaks of $\mathrm{Li}_{2} \mathrm{TiO}_{3}$ are found. The diffraction peaks of $\mathrm{Li}_{4} \mathrm{SiO}_{4}$ shift to small angle with increasing $\mathrm{Ti}$ content, and the increase in the lattice volumes shown in Table 1 indicates the insertion of $\mathrm{Ti}$ in the $\mathrm{Li}_{4} \mathrm{SiO}_{4}$ structure. However, the deviation of $\mathrm{Li}_{2} \mathrm{TiO}_{3}$ peaks does not occur, which reveals the entrance of $\mathrm{Si}$ into $\mathrm{Li}_{2} \mathrm{TiO}_{3}$ lattice is rather difficult. More secondary $\mathrm{Li}_{2} \mathrm{TiO}_{3}$ can be observed in $x=0.2$ sample. This is due to the low content of $\mathrm{Li}_{2} \mathrm{CO}_{3}$ in the precursor, so $\mathrm{Li}_{2} \mathrm{TiO}_{3}$ is retained. Previous researches show that $\mathrm{Li}_{2} \mathrm{TiO}_{3}$ can hardly be incorporated into the $\mathrm{Li}_{4} \mathrm{SiO}_{4}$ giving $\mathrm{Li}_{4} \mathrm{Si}_{1-x} \mathrm{Ti}_{x} \mathrm{O}_{4}$ solid solution [26, 27]. Hence, the possible formation process of $\mathrm{Li}_{4} \mathrm{Si}_{1-x} \mathrm{Ti}_{x} \mathrm{O}_{4}$ in this work can be concluded as: $\mathrm{Li}_{2} \mathrm{TiO}_{3}$ reacts with $\mathrm{Li}_{2} \mathrm{CO}_{3}$ to form $\mathrm{Li}_{4} \mathrm{TiO}_{4}$, subsequently incorporates into $\mathrm{Li}_{4} \mathrm{SiO}_{4}$ to generate solid solution [28]. 


$$
\begin{aligned}
& \mathrm{Li}_{2} \mathrm{TiO}_{3}+\mathrm{Li}_{2} \mathrm{CO}_{3} \rightarrow \mathrm{Li}_{4} \mathrm{TiO}_{4}+\mathrm{CO}_{2} \\
& x \mathrm{Li}{ }_{4} \mathrm{TiO} \mathrm{O}_{4}+\mathbf{\Upsilon}_{x} \mathrm{Hi}_{4} \mathrm{SiO}_{4} \rightarrow \mathrm{Li}_{4} \mathrm{Si}_{1-x} \mathrm{Ti}_{x} \mathrm{O}_{4}
\end{aligned}
$$

\subsection{Morphology of ceramic pebbles}

Fig. 4 shows the cross-section $\mathrm{SEM}$ micrographs of $\mathrm{Li}_{4} \mathrm{Si}_{1-x} \mathrm{Ti}_{x} \mathrm{O}_{4}$ pebbles $(x=0$, $0.05,0.1,0.2$ ). It can be seen that the $\mathrm{Li}_{4} \mathrm{SiO}_{4}$ sample is made of spherical particles and displays the fracture features of intergranular fracture, which indicate the intergranular bonding is weak. In contrast, the $\mathrm{Li}_{4} \mathrm{Si}_{1-x} \mathrm{Ti}_{x} \mathrm{O}_{4}$ samples mainly display irregular particles, and stable polygonal structure can be seen (pointed out by red arrows), which indicates that addition of Ti enhances the sinterability. The migration of interface under the interface driving force is responsible for the growth of polygonal grains. Furthermore, the grain size increases with increasing Ti content. The average grain sizes are $0.80 \mu \mathrm{m}, 3.21 \mu \mathrm{m}, 4.09 \mu \mathrm{m}$ and $5.73 \mu \mathrm{m}$, respectively. It has been reported that the grain growth of $\mathrm{Li}_{4} \mathrm{SiO}_{4}$ pebbles is controlled by the lattice diffusion (volume diffusion) at about $850^{\circ} \mathrm{C}[29]$. As discussed above, Ti substitution increases the lattice diffusion, i.e., the activation energy for grain growth decreases and grains grow more easily for the Ti doped samples under the same sintering conditions. Additionally, the proportion of transgranular fracture rises with increasing Ti doping content (pointed out by yellow arrows), suggesting the enhancement of the grain boundary cohesion. The transgranular fracture feature predicts the enhanced mechanical strength.

EDS mapping was performed on the $\mathrm{Li}_{4} \mathrm{Si}_{0.9} \mathrm{Ti}_{0.1} \mathrm{O}_{4}$ sample to depict the distribution of Ti and Si elements. As shown in Fig. 5, Ti and Si elements are detected within the grains, confirming the formation of solid solution. However, the aggregation of Ti element can be found in some regions (marked with red circles). Combined with the XRD results, it can be deduced the small-sized $\mathrm{Li}_{2} \mathrm{TiO}_{3}$ particles 
exist as second phase.

\subsection{Crush load, density and grain size}

The ceramic pebbles need high crush load to prevent the breaking and fragmentation, which lead to plugging of purge circuits and diminished heat transfer [23]. The dependence of crush load, density and grain size on Ti doping amount is illustrated in Fig. 6. The $\mathrm{Li}_{4} \mathrm{SiO}_{4}$ sample shows low crush load of $11 \mathrm{~N}$, and the crush load is remarkably improved with the increase of $\mathrm{Ti}$ doping content. The average crush loads are $27 \mathrm{~N}(x=0.05), 31 \mathrm{~N}(x=0.1)$ and $52 \mathrm{~N}(x=0.2)$, respectively. Furthermore, the addition of $\mathrm{Ti}$ promotes the grain growth, but has relatively little effect on densification of ceramic pebbles. The ceramic densification is depended on the competition between grain boundary migration and pores removal. The results show that the effect of Ti doping on grain boundary migration prevails. And this is the reason why the density of Ti doped samples is not significantly improved compared to that of $\mathrm{Li}_{4} \mathrm{SiO}_{4}$ sample.

Grain size and porosity are critical factors affecting the strength of ceramics, which can be expressed by the empirical equation [30]: $S=\mathrm{kG}^{-\mathrm{a}} \mathrm{e}^{-\mathrm{bP}}$. Where $\mathrm{S}$ is the strength, $\mathrm{G}$ is the grain size, $\mathrm{P}$ is the porosity, $\mathrm{b}$ is a constant related to pore shape, and $\mathrm{k}$, a are positive constants. The $\mathrm{Li}_{4} \mathrm{Si}_{1-x} \mathrm{Ti}_{x} \mathrm{O}_{4}$ samples have a comparable density (78.5 81.0\%T.D.) and larger grain size, but higher crushing strength, compared to the $\mathrm{Li}_{4} \mathrm{SiO}_{4}$ sample. The reasons for this phenomenon are, on one side, with increasing Ti content, the lattice distortion increases and the deformation resistance of the matrix is increased, thereby resulting in a more significant solid solution strengthening effect. On the other side, second phase $\mathrm{Li}_{2} \mathrm{TiO}_{3}$ contained in the $\mathrm{Li}_{4} \mathrm{Si}_{1-x} \mathrm{Ti}_{x} \mathrm{O}_{4}$ samples may make contribution for the enhanced strength as the crushing strength of $\mathrm{Li}_{2} \mathrm{TiO}_{3}$ is better than that of $\mathrm{Li}_{4} \mathrm{SiO}_{4}$. It also should be noted that strength of ceramic pebbles is 
also affected by flaws, sphericity and impurities.

\subsection{Thermal conductivity}

Thermal conductivity can be calculated by multiplying specific heat, thermal diffusivity and density.

$$
k=\rho \cdot \alpha \cdot c_{p}
$$

where $k$ is thermal conductivity, $\rho$ is bulk density. $\alpha$ and $c_{p}$ are thermal diffusivity and specific heat, which can be directly measured by laser flash apparatus.

Fig. 7 shows the dependence of the thermal diffusivity, specific heat and thermal conductivity on the temperature and Ti doping amount. The relative densities of the pellets are $84.10 \% \quad(x=0), 80.16 \% \quad(x=0.05), 81.53 \% \quad(x=0.1), 81.57 \% \quad(x=0.2)$, respectively. It can be seen that the thermal diffusivity and specific heat of the $\mathrm{Ti}$ doped samples are roughly higher than that of the $\mathrm{Li}_{4} \mathrm{SiO}_{4}$ sample. The thermal conductivity does not increase monotonically with the increase of Ti content, and the $x=0.05$ sample has the best thermal conductivity. Compared with the reported $\mathrm{Li}_{4+x} \mathrm{Si}_{1-x} \mathrm{Al}_{x} \mathrm{O}_{4}$ [17], the prepared $\mathrm{Li}_{4} \mathrm{Si}_{1-x} \mathrm{Ti}_{x} \mathrm{O}_{4}$ in this work exhibits lower thermal conductivity. There may be two reasons: (1) Heat conduction of $\mathrm{Li}_{4} \mathrm{SiO}_{4}$ can be carried out through photons and carriers. The formation of interstitial lithium, as the result of aluminum addition, contributes to the thermal conductivity. (2) Generally, thermal conductivity decreases with increasing porosity and is very sensitive to impurities. Hence, the presence of pores and $\mathrm{Li}_{2} \mathrm{TiO}_{3}$ may be detrimental to the thermal conductivity. Even so, the thermal conductivity of $\mathrm{Li}_{4} \mathrm{SiO}_{4}$ is obviously improved through the substitution of $\mathrm{Ti}$, it is foreseen that solid solution ceramics should be a good candidate for advanced tritium breeders.

\subsection{Ion conductivity}

Tritium diffusion process can be envisaged as lithium-ion migration which acts 
as the charge carrier in the ceramics $[22,31]$, the tritium release behavior can be evaluated by measuring the conductivity of breeder materials. Fig. 8 are the impedance spectra of the samples recorded at room temperature in the frequency range of $100 \sim 10^{6} \mathrm{~Hz}$. The equivalent circuit is composed of a resistance R1 in series with a component consisting of another resistance $\mathrm{R} 2$ in parallel to a CPE element. The depressed semicircle is present in the plot, the right intercept of the semicircle with the real axis corresponds to the bulk resistance (grain interior resistance plus grain boundary resistance). The ion conductivity can be calculated in accordance with the relation:

$$
\sigma=\frac{L}{R \cdot S}
$$

where $\sigma$ is ion conductivity, $L$ is the sample thickness, $R$ is the bulk resistance and $S$ is the area of of the electrode. The calculated ion conductivity is illustrated in Table 2. It can be seen that substitution of $\mathrm{Ti}$ for $\mathrm{Si}$ causes an increase in ionic conductivity, signifying the improvement in tritium release performance. The insertion of $\mathrm{Ti}^{4+}$ enlarges the lattice size of the $\mathrm{Li}_{4} \mathrm{SiO}_{4}$-type structure, i.e. the size of migration channels of $\mathrm{Li}^{+}$increases [32]. Moreover, since $\mathrm{Ti}-\mathrm{O}$ bond is stronger than $\mathrm{Si}-\mathrm{O}$ bond, the $\mathrm{Li}-\mathrm{O}$ bond interaction in $\mathrm{Li}_{4} \mathrm{SiO}_{4}$ structure is decreased when the $\mathrm{Si}$ atom is replaced by Ti atom, thus the ionic conductivity is improved [33]. However, the ionic conductivity decreases with increasing $x$ from 0.1 to 0.2 , this is probably due to the increased proportion of second-phase $\mathrm{Li}_{2} \mathrm{TiO}_{3}$. According to the research by Tanigawa et al. [34], lithium orthosilicate has better conductivity than lithium titanate, and the electrical conductivity of $\mathrm{Li}_{4} \mathrm{SiO}_{4}$ is about two orders larger than that of $\mathrm{Li}_{2} \mathrm{TiO}_{3}$ at $975 \mathrm{~K}$.

\subsection{Thermal cycling}

It is important to study the microstructure and crushing strength changes during 
the thermal cycling tests. As shown in Fig. 9, the grain size of $\mathrm{Li}_{4} \mathrm{SiO}_{4}$ sample increases following thermal cycles, small-sized pores merge with each other, and coarse grains with a transgranular fracture morphology can be observed. EDS analyses indicate both fine grains and coarse grains in Fig. 9 b2 are $\mathrm{Li}_{4} \mathrm{SiO}_{4}$ (Fig. S1 and S2), confirming the secondary growth of grains. The crush load increases slightly after 9 cycles (Fig. 13a), which is ascribed to the change of fracture mode and the decrease of pores. However, due to the presence of intracrystalline pores and cracks, the crush load decreases after 12 cycles.

For the $\mathrm{Li}_{4} \mathrm{Si}_{0.95} \mathrm{Ti}_{0.05} \mathrm{O}_{4}$ sample, no obvious changes in the microstructure and the crush load after 6 thermal cycles (Fig. 10 and Fig. 13b). Many tiny particles precipitate on the grain boundaries and the surface of grains. EDS analysis (see Fig. $\mathrm{S} 3$ ) shows that $\mathrm{Si} / \mathrm{Ti}$ ratio is lower than the designed value (viz. 8.3 vs 19 ), suggesting the segregation of Ti toward the grain surface during long-time thermal cycling. This can lead to the slight decrease of strength after 9 cycles.

With prolonging the thermal cycling, the microstructure of $\mathrm{Li}_{4} \mathrm{Si}_{0.9} \mathrm{Ti}_{0.1} \mathrm{O}_{4}$ sample changes significantly (Fig. 11) and the strength decreases rapidly (Fig. 13c). EDS analysis confirms the tiny particles as titanium-rich (Fig. S4). The atom ratio of Si:Ti is close to $2.5: 1$ which is much lower than the designed value. It is reasonable to assume that the segregation becomes more serious with the increase of Ti doping content. Furthermore, a great amount of intracrystalline pores can be observed after 12 cycles. As a result, the crush load decreases to less than $20 \mathrm{~N}$, revealing inferior durability of the $\mathrm{Li}_{4} \mathrm{Si}_{0.9} \mathrm{Ti}_{0.1} \mathrm{O}_{4}$ sample.

For the $\mathrm{Li}_{4} \mathrm{Si}_{0.8} \mathrm{Ti}_{0.2} \mathrm{O}_{4}$ sample (Fig. 12), laminate structure mainly composed of $\mathrm{Ti}$ and $\mathrm{O}$ can be seen clearly after 9 cycles (Fig. S5). EDS mapping also indicates Ti with high concentration within the laminate grains (Fig. S6). It suggests the formation 
of titanate. Although the microstructure of the $\mathrm{Li}_{4} \mathrm{Si}_{0.8} \mathrm{Ti}_{0.2} \mathrm{O}_{4}$ sample changes slightly after the thermal cycling, it still exhibits a high crush load (Fig. 13d). Since many factors can affect the strength, such as grain size, porosity, pore size and distribution, sphericity, the content and size of second-phases, humidity, etc., the variation in strength with thermal cycling periods is irregular.

To sum up, the moderate amount of Ti doping can improve the mechanical and physical properties and thermal cycling stability of $\mathrm{Li}_{4} \mathrm{SiO}_{4}$. Compared with Al-doped $\mathrm{Li}_{4} \mathrm{SiO}_{4}[17,19,20]$, Ti doping plays a more significant role in enhancing crushing strength, whilst $\mathrm{Al}$ doping contributes more to the the improvement of conductivity. Tritium release experiments conducted by $\mathrm{Zhao}$ et al. revealed that $\mathrm{Li}_{4.2} \mathrm{Si}_{0.8} \mathrm{Al}_{0.2} \mathrm{O}_{4}$ had lower tritium release temperature and potentially better irradiation resistance compared to $\mathrm{Li}_{4} \mathrm{SiO}_{4}$ [18]. The tritium release performance and irradiation resistance of $\mathrm{Li}_{4} \mathrm{Si}_{1-x} \mathrm{Ti}_{x} \mathrm{O}_{4}$ solid solution are also worthy of expectation ( $\mathrm{Ti}$ has lower neutron activation than $\mathrm{Al}$ ). Since the thermal cycling stability of $\mathrm{Li}_{4+x} \mathrm{Si}_{1-x} \mathrm{Al}_{x} \mathrm{O}_{4}$ pebbles has not been reported, we cannot make a comparison yet. View from the current studies, solid solution materials should have unique advantages in advanced tritium breeding materials, although more deep studies are still required to further understand the influence of various doping elements.

\section{Conclusions}

The $\mathrm{Li}_{4} \mathrm{Si}_{1-\mathrm{x}} \mathrm{Ti}_{\mathrm{x}} \mathrm{O}_{4}$ ceramic pebbles were successfully prepared by proprietary hydrothermal process and multistage sintering. The formation of $\mathrm{Li}_{4} \mathrm{Si}_{1-x} \mathrm{Ti}_{x} \mathrm{O}_{4}$ solid solution may be result from the incorporation of $\mathrm{Li}_{4} \mathrm{TiO}_{4}$ into $\mathrm{Li}_{4} \mathrm{SiO}_{4}$. Ti-doping can promote the sinterability and grain growth of $\mathrm{Li}_{4} \mathrm{SiO}_{4}$. The crush load of the $\mathrm{Li}_{4} \mathrm{SiO}_{4}$ pebbles is improved significantly by doping $\mathrm{Ti}$, and it increases almost four times by increasing $x$ from 0 to 0.2 . The thermal and ionic conductivity do not increase 
monotonically with increasing Ti content, the best values are obtained when $x=0.05$ and $x=0.1$, respectively. Thermal cycling tests display that the $\mathrm{Li}_{4} \mathrm{Si}_{1-x} \mathrm{Ti}_{x} \mathrm{O}_{4}$ samples still have higher crush load compared with the $\mathrm{Li}_{4} \mathrm{SiO}_{4}$ sample, despite Ti segregation in some samples after undergoing thermal cycling. With the increase of Ti doping content, the segregation becomes more serious. In terms of thermal stability, the optimal Ti doping amount should be $x=0.05$. As titanium has low neutron activation behavior, $\mathrm{Li}_{4} \mathrm{Si}_{1-x} \mathrm{Ti}_{x} \mathrm{O}_{4}$ solid solution may have good application prospect in the field of solid tritium breeders.

\section{Acknowledgment}

This work is supported by National Natural Science Foundation of China (Nos. 51802257), Natural Science Foundation of Shaanxi Provincial Department of Education (18JK0570) and China Postdoctoral Science Foundation (2019M663788).

\section{References}

[1] M. Xiang, C. Wang, Y. Zhang, et al., Research Progress of Fabrication Process for Solid State Tritium Breeders, Adv Ceram 37 (4) (2016) 241-252.

[2] S. Konishi, M. Enoeda, M. Nakamichi, et al., Functional materials for breeding blanketsd—status and developments, Nucl. Fusion 57 (9) (2017) 092014.

[3] K. Feng, X. Wang, Y. Feng, et al., Current progress of Chinese HCCB TBM program, Fusion Eng. Des. 109 (2016) 729-735.

[4] K. Tsuchiya, T. Hoshino, H. Kawamura, et al., Development of advanced tritium breeders and neutron multipliers for DEMO solid breeder blankets, Nuclear Fusion 47 (9) (2007) 1300.

[5] U. Dash, S. Sahoo, P. Chaudhuri, et al., Electrical properties of bulk and nano $\mathrm{Li}_{2} \mathrm{TiO}_{3}$ ceramics: A comparative study, J Adv Ceram 3 (2) (2014) 89-97. 
[6] J. Li, Y. Wan, Present state of Chinese magnetic fusion development and future plans, J. Fusion Energy 38 (1) (2019) 113-124.

[7] T. Hoshino. Pebble fabrication of super advanced tritium breeders using a solid solution of $\mathrm{Li}_{2+\mathrm{x}} \mathrm{TiO}_{3+\mathrm{y}}$ with $\mathrm{Li}_{2} \mathrm{ZrO}_{3}$, Nucl. Mater. Energy 9 (2016) 221-226.

[8] T. Hoshino, Y. Edao, Y. Kawamura, et al., Pebble fabrication and tritium release properties of an advanced tritium breeder, Fusion Eng. Des. 109 (2016) $1114-1118$.

[9] T. Hoshino, K. Ochiai, Y. Edao, et al., Evaluation of tritium release properties of advanced tritium breeders, Fusion Sci. Technol. 67 (2) (2015) 386-389.

[10]Y. Wang, Q. Zhou, L. Xue, et al., Synthesis of the biphasic mixture of $\mathrm{Li}_{2} \mathrm{TiO}_{3}-\mathrm{Li}_{4} \mathrm{SiO}_{4}$ and its irradiation performance, J. Eur. Ceram. Soc. 36(16) (2016) 4107-4113.

[11]Y. Zhai, J. Hu, Y. Duan, et al., Characterization of tritium breeding ceramic pebbles prepared by melt spraying, J. Eur. Ceram. Soc. 40 (4) (2020) 1602-1612.

[12] G.J. Rao, R. Mazumder, S. Bhattacharyya, et al., Fabrication of $\mathrm{Li}_{4} \mathrm{SiO}_{4}-\mathrm{Li}_{2} \mathrm{ZrO}_{3}$ composite pebbles using extrusion and spherodization technique with improved crush load and moisture stability, J. Nucl. Mater. 514 (2019) 321-333.

[13] M.H.H. Kolb, R. Knitter, T. Hoshino. $\mathrm{Li}_{4} \mathrm{SiO}_{4}$ based breeder ceramics with $\mathrm{Li}_{2} \mathrm{TiO}_{3}, \mathrm{LiAlO}_{2}$ and $\mathrm{Li}_{x} \mathrm{La}_{\mathrm{y}} \mathrm{TiO}_{3}$ additions, part II: Pebble properties, Fusion Eng. Des. 115 (2017) 6-16.

[14]A. Zarins, O. Valtenbergs, G. Kizane, et al., Formation and accumulation of radiation-induced defects and radiolysis products in modified lithium 
orthosilicate pebbles with additions of titanium dioxide, J. Nucl. Mater. 470 (2016) 187-196

[15]R. Knitter, B. Löbbecke, Reprocessing of lithium orthosilicate breeder material by remelting, J. Nucl. Mater. 361 (1) (2007) 104-111

[16]M. Wang, M. Xiang, Y. Zhang, Fabrication and characterization of $\mathrm{Li}_{4} \mathrm{SiO}_{4}$ ceramic pebbles doped with $\mathrm{Y}_{2} \mathrm{O}_{3}$ and $\mathrm{Nb}_{2} \mathrm{O}_{5}$, Solid State Phenom. 281 (2018) $28-33$.

[17]L. Zhao, X. Long, X. Chen, et al., Design, synthesis and characterization of the advanced tritium breeder: $\mathrm{Li}_{4+\mathrm{x}} \mathrm{Si}_{1-\mathrm{x}} \mathrm{Al}_{\mathrm{x}} \mathrm{O}_{4}$ ceramics, J. Nucl. Mater. 467 (2015) 911-916.

[18]L. Zhao, X. Long, S. Peng, et al., Tritium release in $\mathrm{Li}_{4} \mathrm{SiO}_{4}$ and $\mathrm{Li}_{4.2} \mathrm{Si}_{0.8} \mathrm{Al}_{0.2} \mathrm{O}_{4}$ ceramics, J. Nucl. Mater. 482 (2016) 42-46.

[19]M. Xiang, Y. Zhang, Y. Zhang, et al., Preparation, performances and reaction mechanism of the $\mathrm{Li}_{4+\mathrm{x}} \mathrm{Si}_{1-\mathrm{x}} \mathrm{Al}_{\mathrm{x}} \mathrm{O}_{4}$ pebbles for advanced tritium breeders, Fusion Eng. Des. 116 (2017) 17-23.

[20]Y. Gong, J. Li, S. Yang, et al., Improvement of crushing strength and thermal conductivity by introduction of hetero-element $\mathrm{Al}$ into $\mathrm{Li}_{4} \mathrm{SiO}_{4}$, Ceram. Int. 45 (18) (2019) 24564-24569.

[21]Y. Saito, T. Asai, K. Ado, et al., Ionic conductivity of $\mathrm{Li}^{+}$ion conductors $\mathrm{Li}_{4.2} \mathrm{M}_{\mathrm{x}} \mathrm{Si}_{1-\mathrm{x}} \mathrm{O}_{4}\left(\mathrm{M}: \mathrm{B}^{3+}, \mathrm{Al}^{3+}, \mathrm{Ga}^{3+}, \mathrm{Cr}^{3+}, \mathrm{Fe}^{3+}, \mathrm{Co}^{2+}, \mathrm{Ni}^{2+}\right)$, Solid State Ionics 40/41 (1990) 34-37.

[22]U. Dash, S. Sahoo, S.K.S. Parashar, et al., Effect of $\mathrm{Li}^{+}$ion mobility on the grain 
boundary conductivity of $\mathrm{Li}_{2} \mathrm{TiO}_{3}$ nanoceramics, J Adv Ceram 3 (2) (2014) 98-108.

[23]N. Roux, C. Johnson, K. Noda. Properties and performance of tritium breeding ceramics, J. Nucl. Mater. 191 (1992) 15-22.

[24]X. Wu, Z. Wen, X. Xu, et al., Synthesis and characterization of $\mathrm{Li}_{4} \mathrm{SiO}_{4}$ nano-powders by a water-based sol-gel process, J. Nucl. Mater. 392 (3) (2009) $471-475$.

[25]C.E. Johnson, T. Kondo, N. Roux, et al., Fabrication, properties, and tritium recovery from solid breeder materials, Fusion Eng. Des. 16 (1991) 127-139.

[26]C. Dang, M. Yang, Y. Gong, et al., A promising tritium breeding material: Nanostructured $2 \mathrm{Li}_{2} \mathrm{TiO}_{3}-\mathrm{Li}_{4} \mathrm{SiO}_{4}$ biphasic ceramic pebbles, J. Nucl. Mater. 500 (2018) 265-269.

[27] O. Leys, M.H.H. Kolb, A. Pucci, et al., Study of lithium germanate additions to advanced ceramic breeder pebbles, J. Nucl. Mater. 518 (2019) 234-240.

[28]A.R. West. Ionic conductivity of oxides based on $\mathrm{Li}_{4} \mathrm{SiO}_{4}$, J. Appl. Electrochem. 3 (4) (1973) 327-335.

[29]M. Xiang, Y. Zhang, Y. Zhang, et al., Grain growth behavior of $\mathrm{Li}_{4} \mathrm{SiO}_{4}$ pebbles fabricated by agar method for tritium breeder, Fusion Eng. Des. 112 (2016) $513-519$.

[30]F.P. Knudsen, Dependence of mechanical strength of brittle polycrystalline specimens on porosity and grain size, J. Am. Ceram. Soc. 42 (8) (1959) 376-387

[31]Q. Zhou, L. Xue, Y. Wang, et al., Preparation of $\mathrm{Li}_{2} \mathrm{TiO}_{3}$ ceramic with nano-sized 
pores by ultrasonic-assisted solution combustion, J. Eur. Ceram. Soc. 37 (11) (2017) 3595-3602.

[32]S. Adnan, N.S. Mohamed. Effects of Sn substitution on the properties of $\mathrm{Li}_{4} \mathrm{SiO}_{4}$ ceramic electrolyte, Solid State Ionics 262 (2014) 559-562.

[33]J. Ortiz-Landeros, C. Gómez-Yáñez, L.M. Palacios-Romero, et al., Structural and Thermochemical Chemisorption of $\mathrm{CO}_{2}$ on $\mathrm{Li}_{4+\mathrm{x}}\left(\mathrm{Si}_{1-\mathrm{x}} \mathrm{Al}_{\mathrm{x}}\right) \mathrm{O}_{4}$ and $\mathrm{Li}_{4-\mathrm{x}}\left(\mathrm{Si}_{1-\mathrm{x}} \mathrm{V}_{\mathrm{x}}\right) \mathrm{O}_{4}$ Solid Solutions, J Phys Chem A 116 (12) (2012) 3163-3171.

[34]H. Tanigawa, Y. Tanaka, M. Enoeda, et al., Thermal Conductivity Measurement with Silica-Coated Hot Wire for $\mathrm{Li}_{4} \mathrm{SiO}_{4}$ Pebble Bed, J. Nucl. Sci. Technol. 46 (6) (2009) 553-556. 
Figures

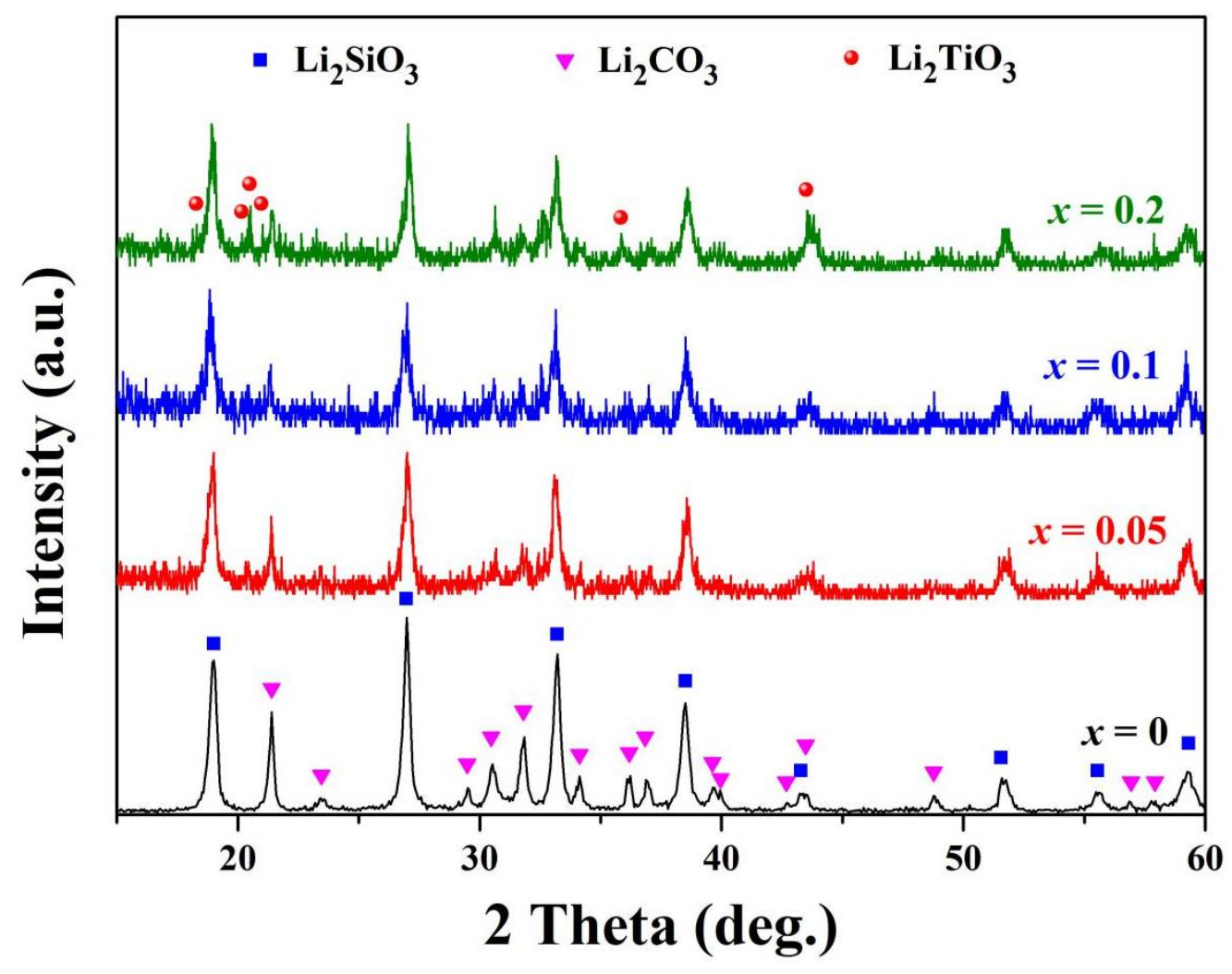

Fig. 1 XRD patterns of the precursor powders synthesized by hydrothermal method
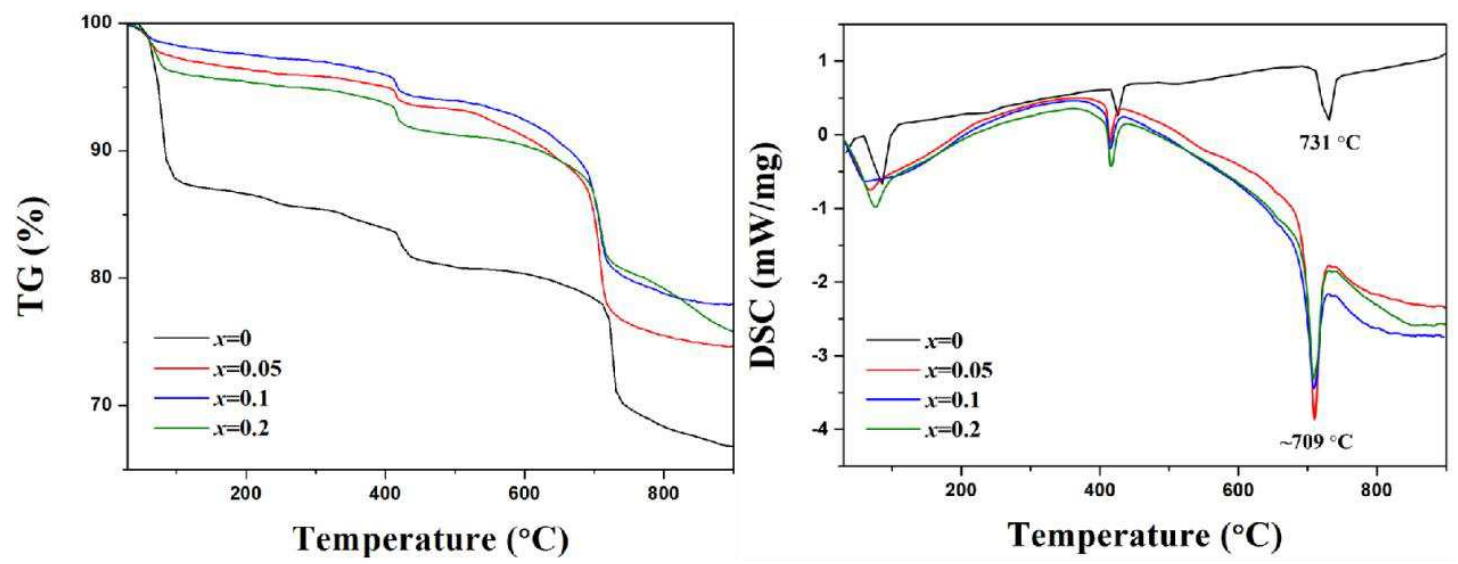

Fig. 2 TG/DSC of the precursor powders 

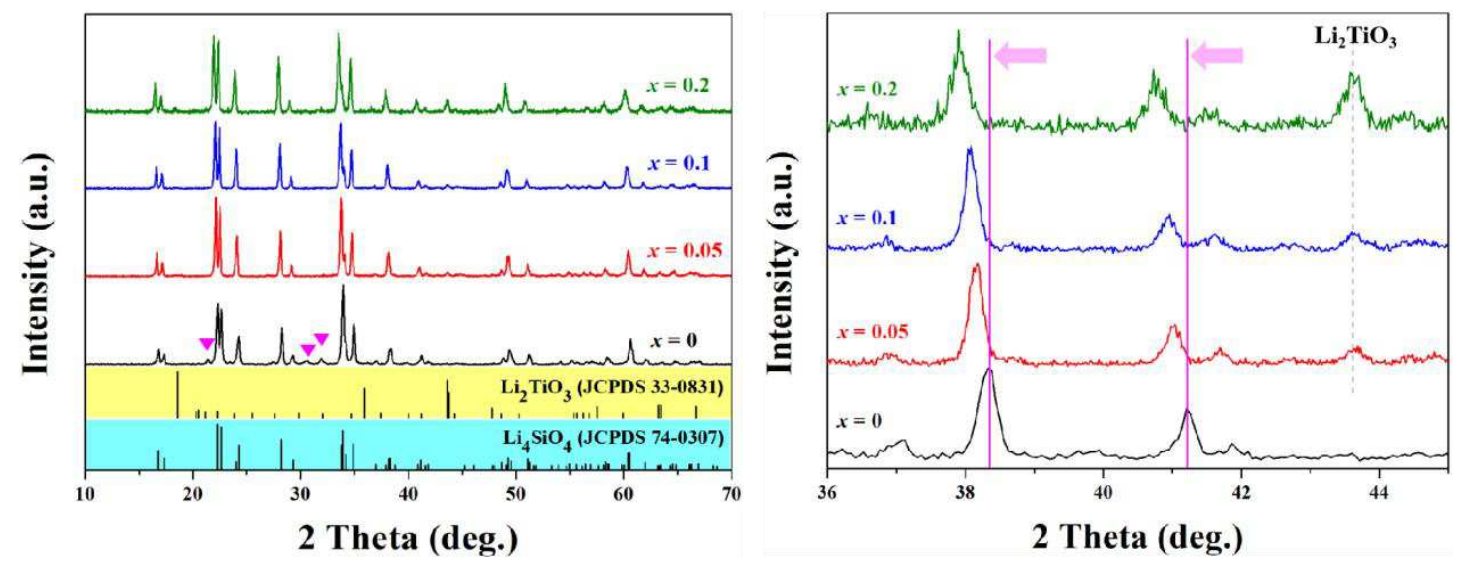

Fig. 3 XRD patterns of $\mathrm{Li}_{4} \mathrm{Si}_{1-x} \mathrm{Ti}_{x} \mathrm{O}_{4}$

Table 1 Rietveld refinement parameters for $\mathrm{Li}_{4} \mathrm{Si}_{1-x} \mathrm{Ti}_{x} \mathrm{O}_{4}$

\begin{tabular}{|c|c|c|c|c|c|c|}
\hline \multirow{2}{*}{ samples } & \multicolumn{3}{|c|}{ cell parameters $(\AA)$} & \multirow{2}{*}{$\beta\left(^{\circ}\right)$} & \multirow{2}{*}{$\begin{array}{l}\text { cell volume } \\
\qquad\left(\AA^{3}\right)\end{array}$} & \multirow{2}{*}{$\begin{array}{l}\text { theoretical density } \\
\qquad\left(\mathrm{g} / \mathrm{cm}^{3}\right)\end{array}$} \\
\hline & $\mathrm{a}$ & $\mathrm{b}$ & $\mathrm{c}$ & & & \\
\hline$x=0$ & 5.14282 & 6.09982 & 5.29247 & 90.2805 & 166.02 & 2.397 \\
\hline$x=0.05$ & 5.15371 & 6.11125 & 5.30074 & 90.2042 & 166.95 & 2.384 \\
\hline$x=0.1$ & 5.16278 & 6.12278 & 5.31046 & 90.276 & 167.86 & 2.371 \\
\hline$x=0.2$ & 5.16304 & 6.1465 & 5.32568 & 89.9426 & 169.01 & 2.355 \\
\hline
\end{tabular}



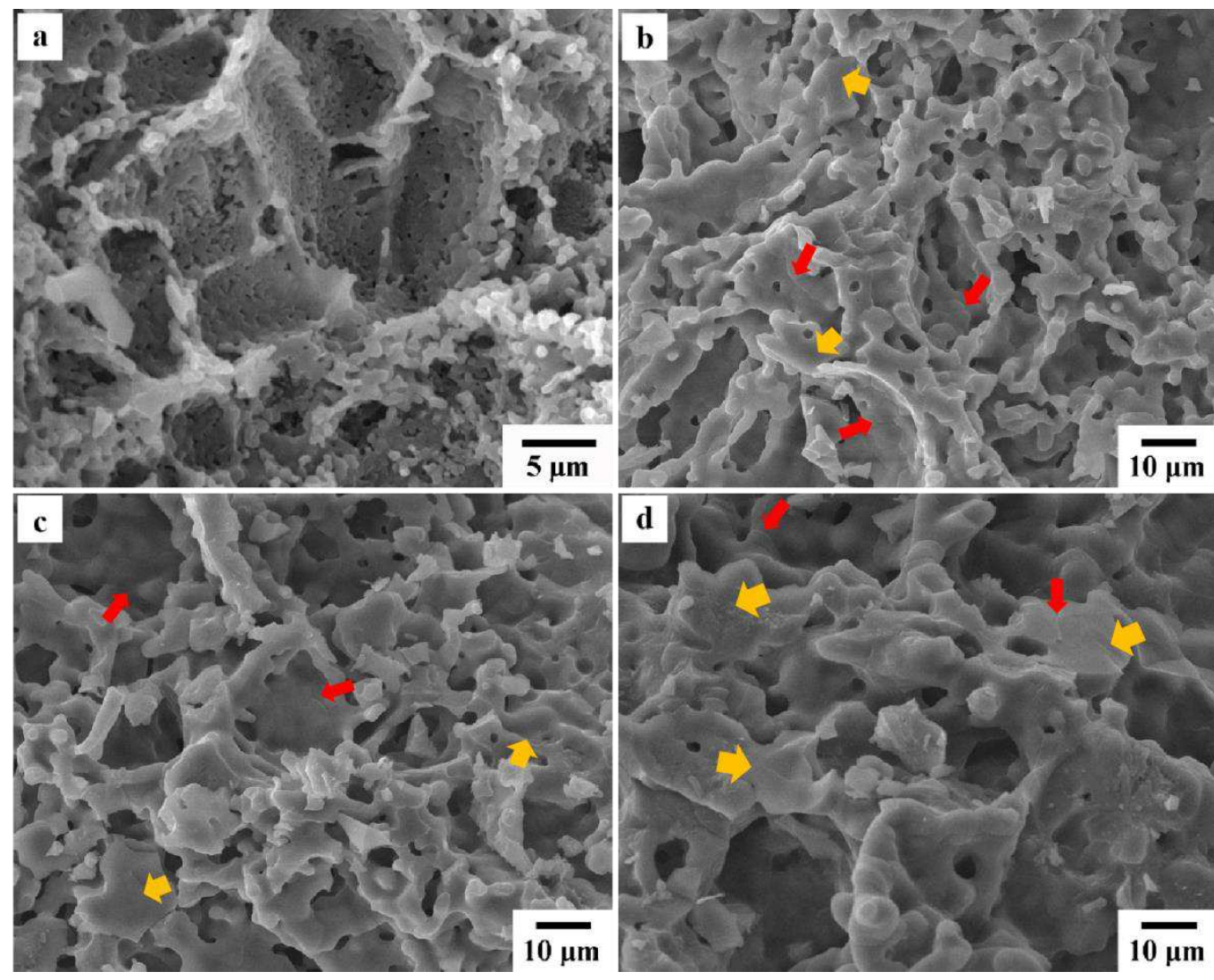

Fig. 4 SEM fracture micrographs of $\mathrm{Li}_{4} \mathrm{Si}_{1-x} \mathrm{Ti}_{x} \mathrm{O}_{4}$ pebbles fabricated via multistage sintering: (a) $x=0$; (b) $x=0.05$; (c) $x=0.1$; (d) $x=0.2$

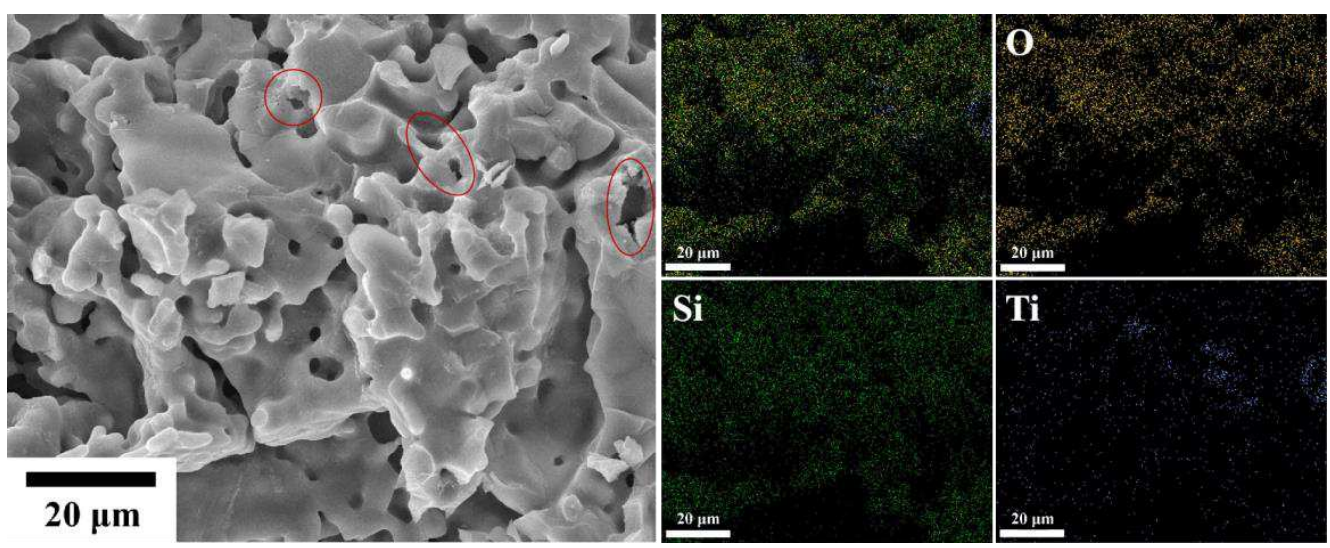

Fig. 5 SEM micrographs of $\mathrm{Li}_{4} \mathrm{Si}_{1-x} \mathrm{Ti}_{x} \mathrm{O}_{4}$ with Ti content $x=0.1$ and corresponding EDS mapping of Si, Ti and O elements 


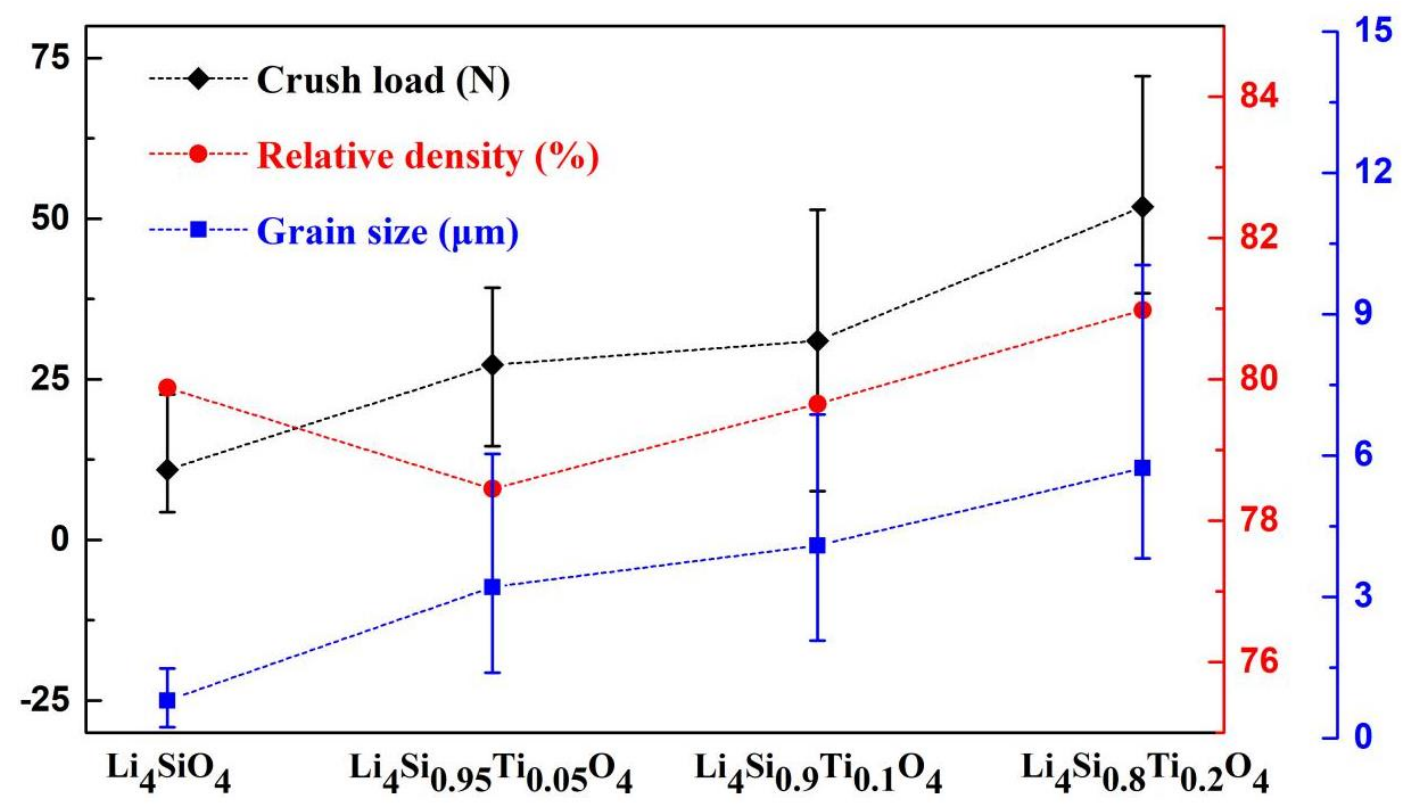

Fig. 6 The dependence of crush load, density and grain size on Ti doping content
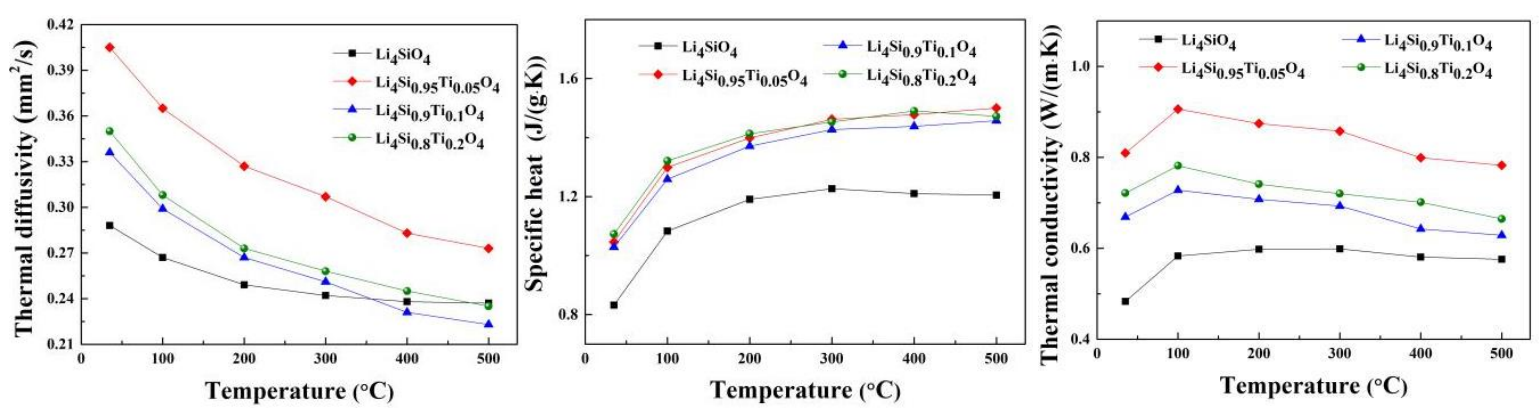

Fig. 7 Thermal diffusivity, specific heat and thermal conductivity of $\mathrm{Li}_{4} \mathrm{Si}_{1-x} \mathrm{Ti}_{x} \mathrm{O}_{4}$ samples $(x=0,0.05,0.1,0.2)$ 


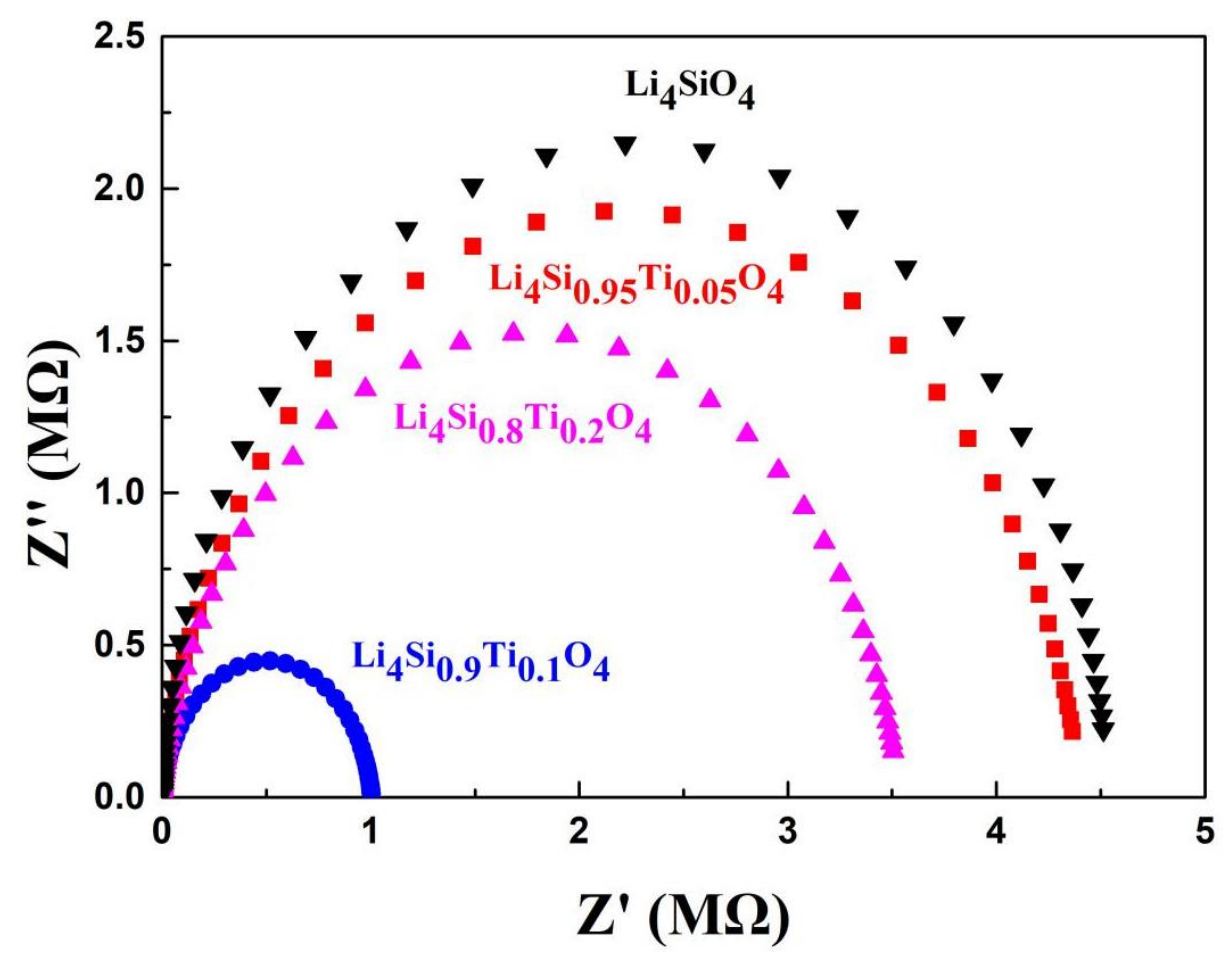

Fig. 8 AC impedance spectra for $\mathrm{Li}_{4} \mathrm{Si}_{1-x} \mathrm{Ti}_{x} \mathrm{O}_{4}$ samples

Table 2 Conductivity of $\mathrm{Li}_{4} \mathrm{Si}_{1-x} \mathrm{Ti}_{x} \mathrm{O}_{4}$ samples

\begin{tabular}{lcccc}
\hline samples & $\mathrm{R}(\Omega)$ & $\mathrm{L}(\mathrm{m})$ & $\mathrm{A}\left(\mathrm{m}^{2}\right)$ & conductivity $(\mathrm{S} / \mathrm{m})$ \\
\hline$x=0$ & $4.512 \times 10^{6}$ & $1.91 \times 10^{-3}$ & $1.5592 \times 10^{-4}$ & $2.715 \times 10^{-6}$ \\
$x=0.05$ & $4.365 \times 10^{6}$ & $2.71 \times 10^{-3}$ & $1.5562 \times 10^{-4}$ & $3.990 \times 10^{-6}$ \\
$x=0.1$ & $1.003 \times 10^{6}$ & $2.64 \times 10^{-3}$ & $1.5562 \times 10^{-4}$ & $1.6914 \times 10^{-5}$ \\
$x=0.2$ & $3.506 \times 10^{6}$ & $2.70 \times 10^{-3}$ & $1.5851 \times 10^{-4}$ & $4.858 \times 10^{-6}$ \\
\hline
\end{tabular}



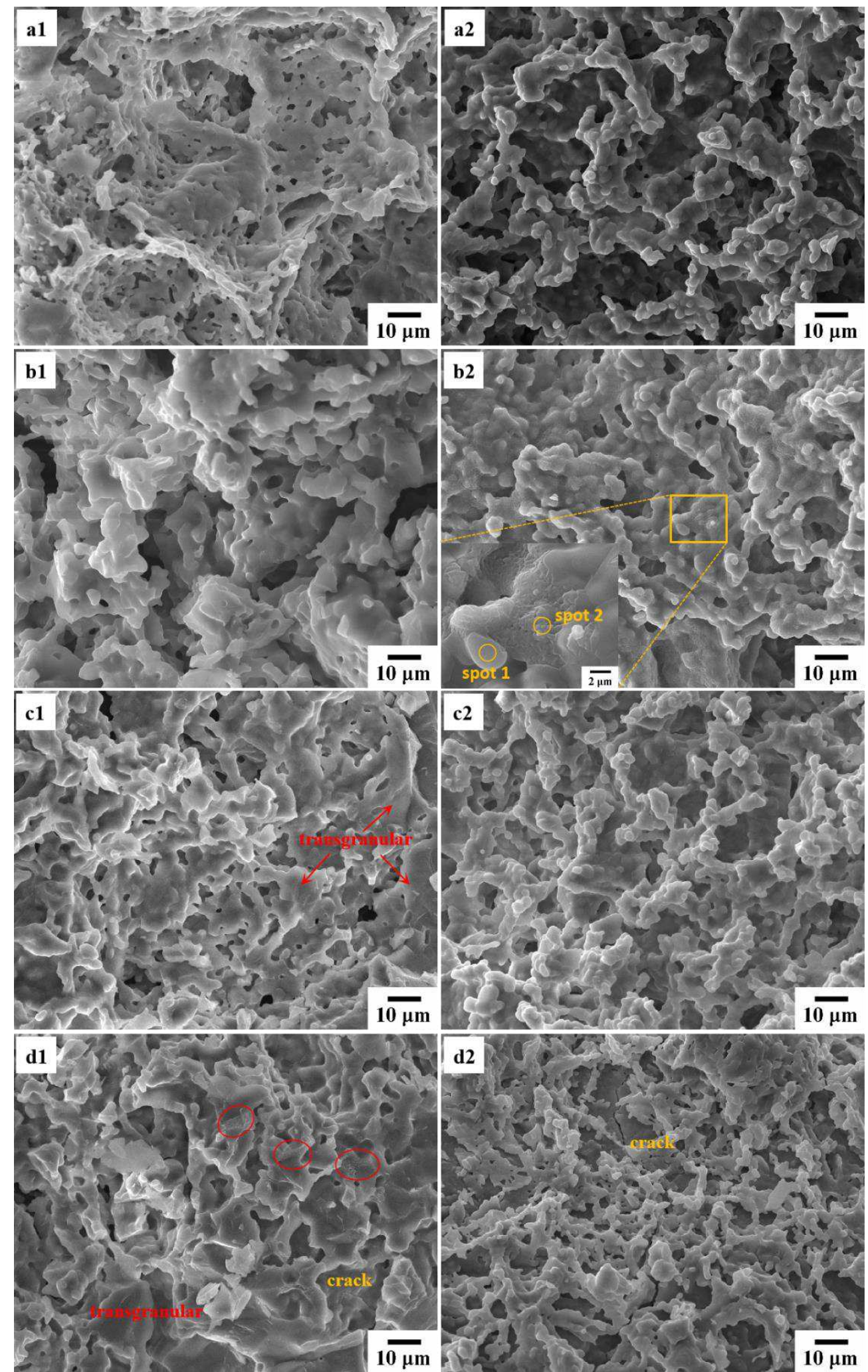

Fig. 9 SEM micrographs of $\mathrm{Li}_{4} \mathrm{SiO}_{4}$ pebbles after (a) 3 cycles, (b) 6 cycles, (c) 9

cycles, (d) 12 cycles. (1) cross section, (2) surface 

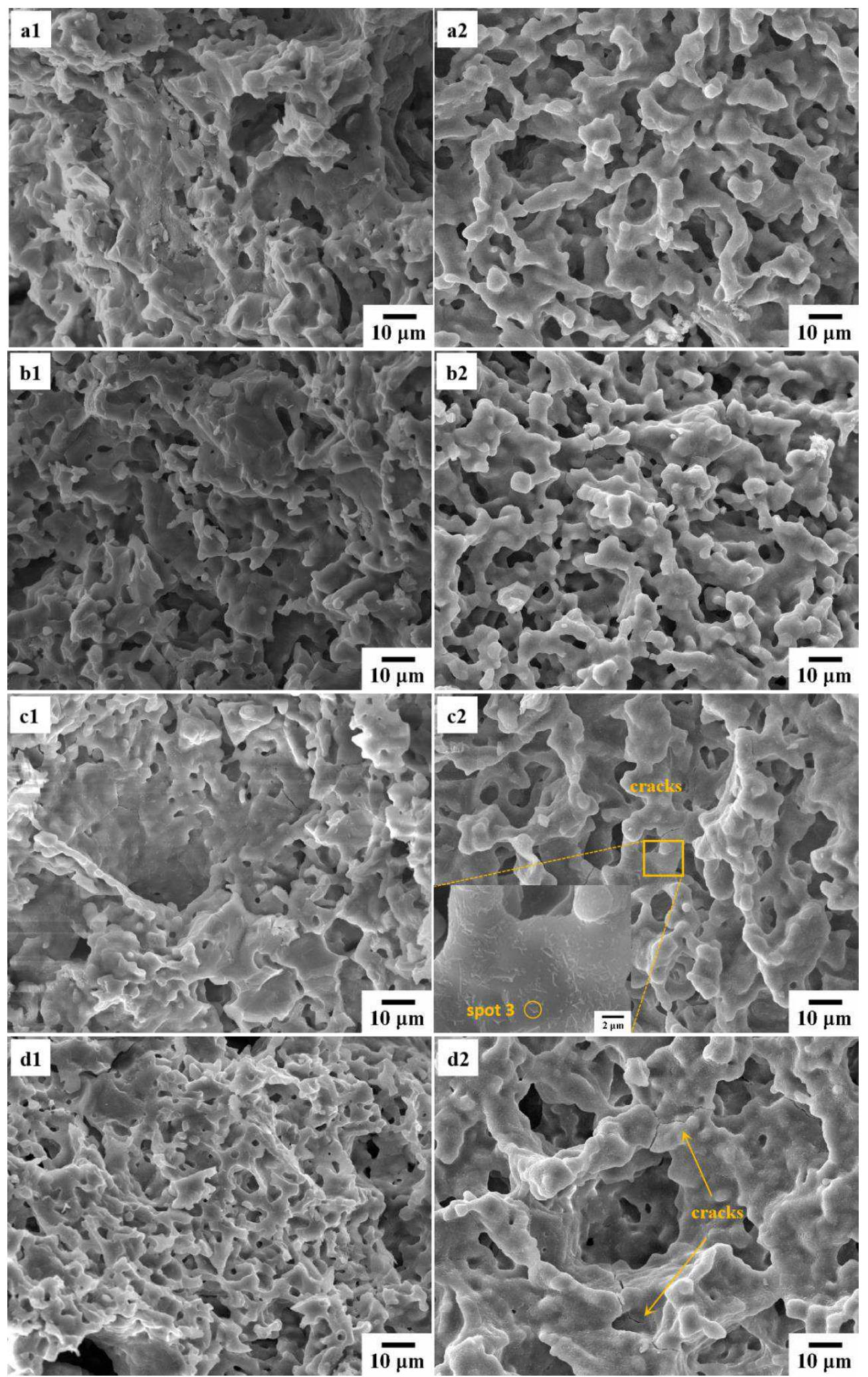

Fig. $10 \mathrm{SEM}$ micrographs of $\mathrm{Li}_{4} \mathrm{Si}_{0.95} \mathrm{Ti}_{0.05} \mathrm{O}_{4}$ pebbles after (a) 3 cycles, (b) 6 cycles,

(c) 9 cycles, (d) 12 cycles. (1) cross section, (2) surface 

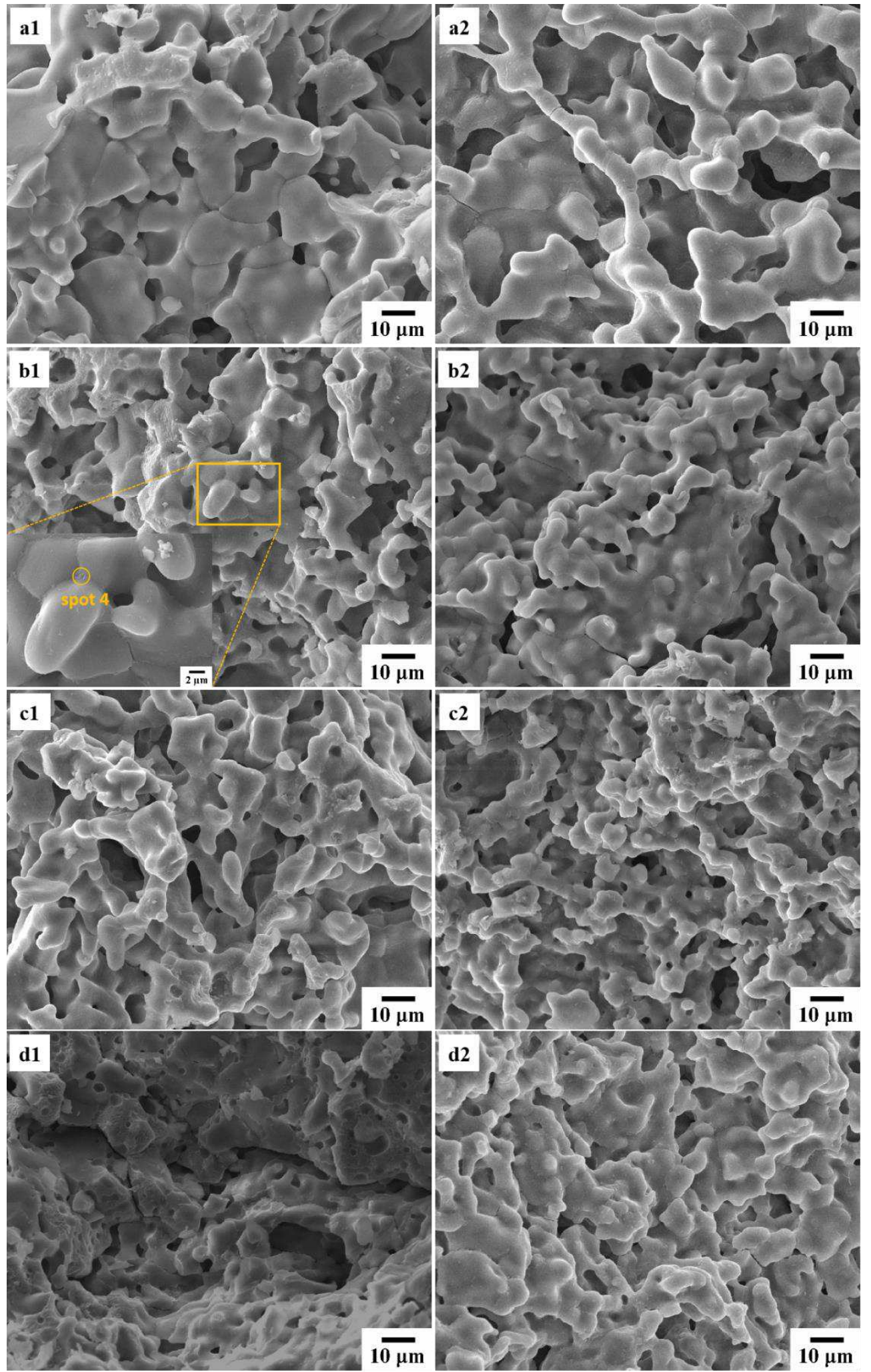

Fig. 11 SEM micrographs of $\mathrm{Li}_{4} \mathrm{Si}_{0.9} \mathrm{Ti}_{0.1} \mathrm{O}_{4}$ pebbles after (a) 3 cycles, (b) 6 cycles, (c)

9 cycles, (d) 12 cycles. (1) cross section, (2) surface 

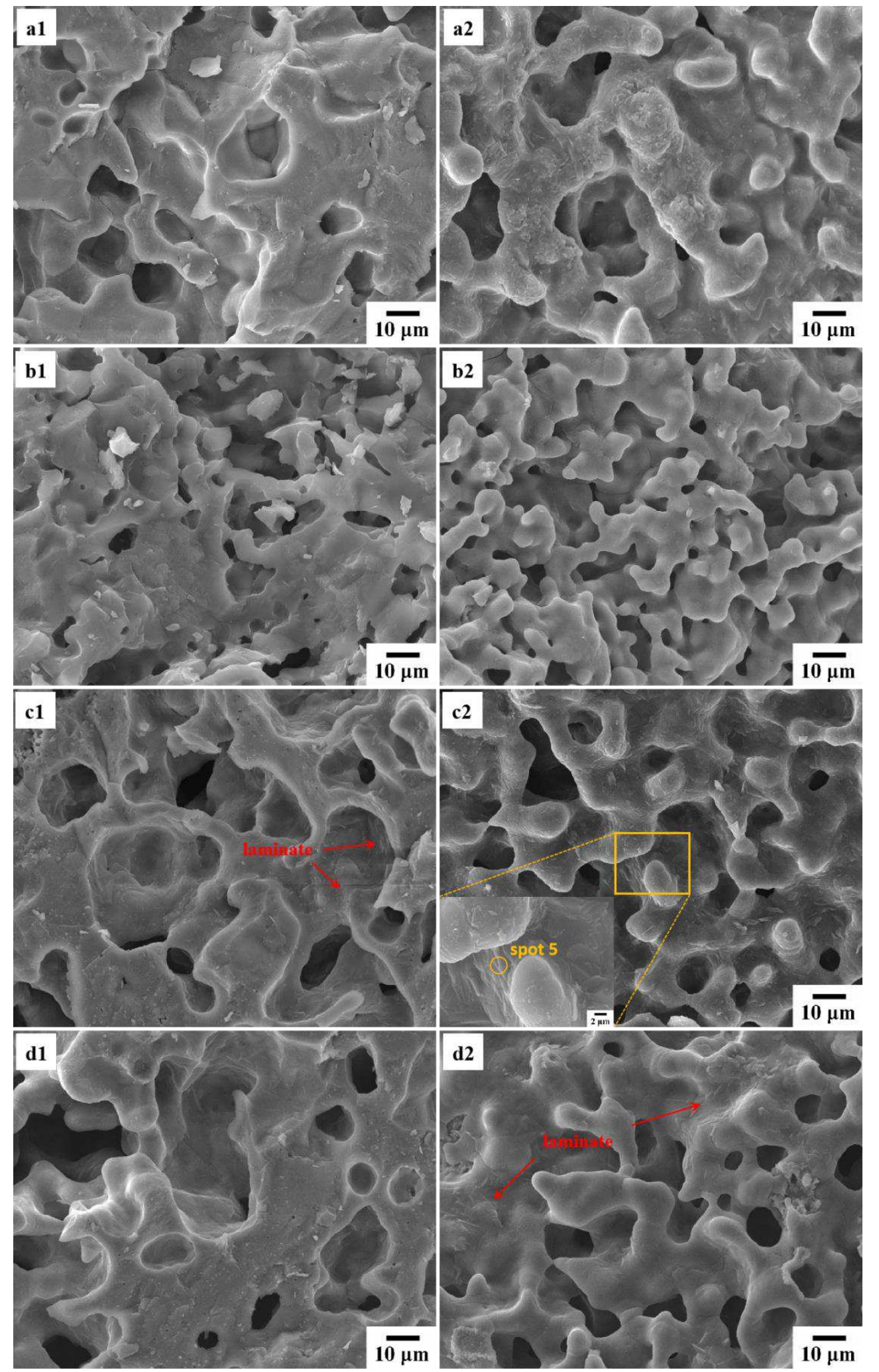

Fig. $12 \mathrm{SEM}$ micrographs of $\mathrm{Li}_{4} \mathrm{Si}_{0.8} \mathrm{Ti}_{0.2} \mathrm{O}_{4}$ pebbles after (a) 3 cycles, (b) 6 cycles, (c)

9 cycles, (d) 12 cycles. (1) cross section, (2) surface 

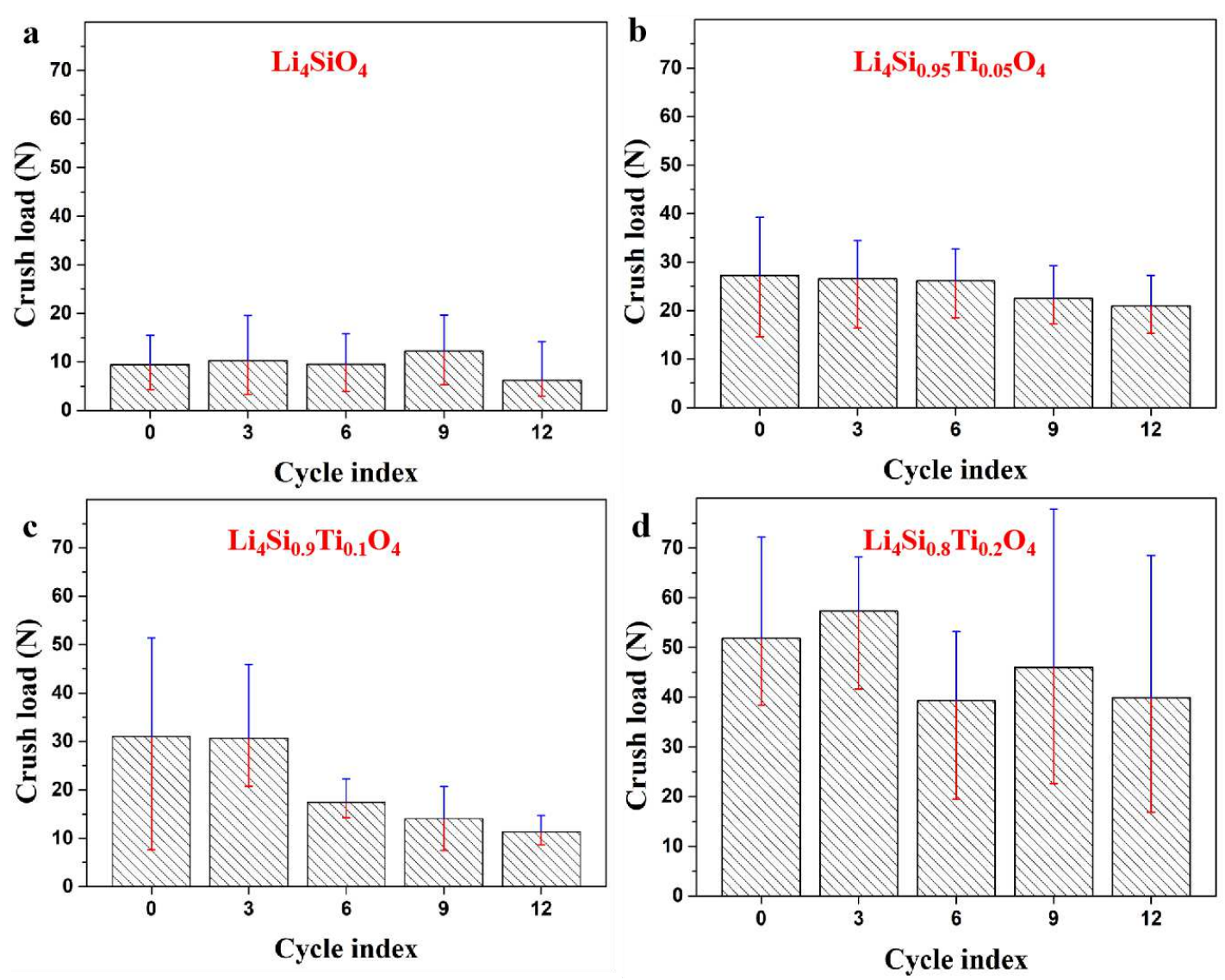

Fig. 13 Relationship between the crush load and thermal cycles: (a) $\mathrm{Li}_{4} \mathrm{SiO}_{4}$ pebbles,

(b) $\mathrm{Li}_{4} \mathrm{Si}_{0.95} \mathrm{Ti}_{0.05} \mathrm{O}_{4}$ pebbles, (c) $\mathrm{Li}_{4} \mathrm{Si}_{0.9} \mathrm{Ti}_{0.1} \mathrm{O}_{4}$ pebbles, (d) $\mathrm{Li}_{4} \mathrm{Si}_{0.8} \mathrm{Ti}_{0.2} \mathrm{O}_{4}$ pebbles 
Figures

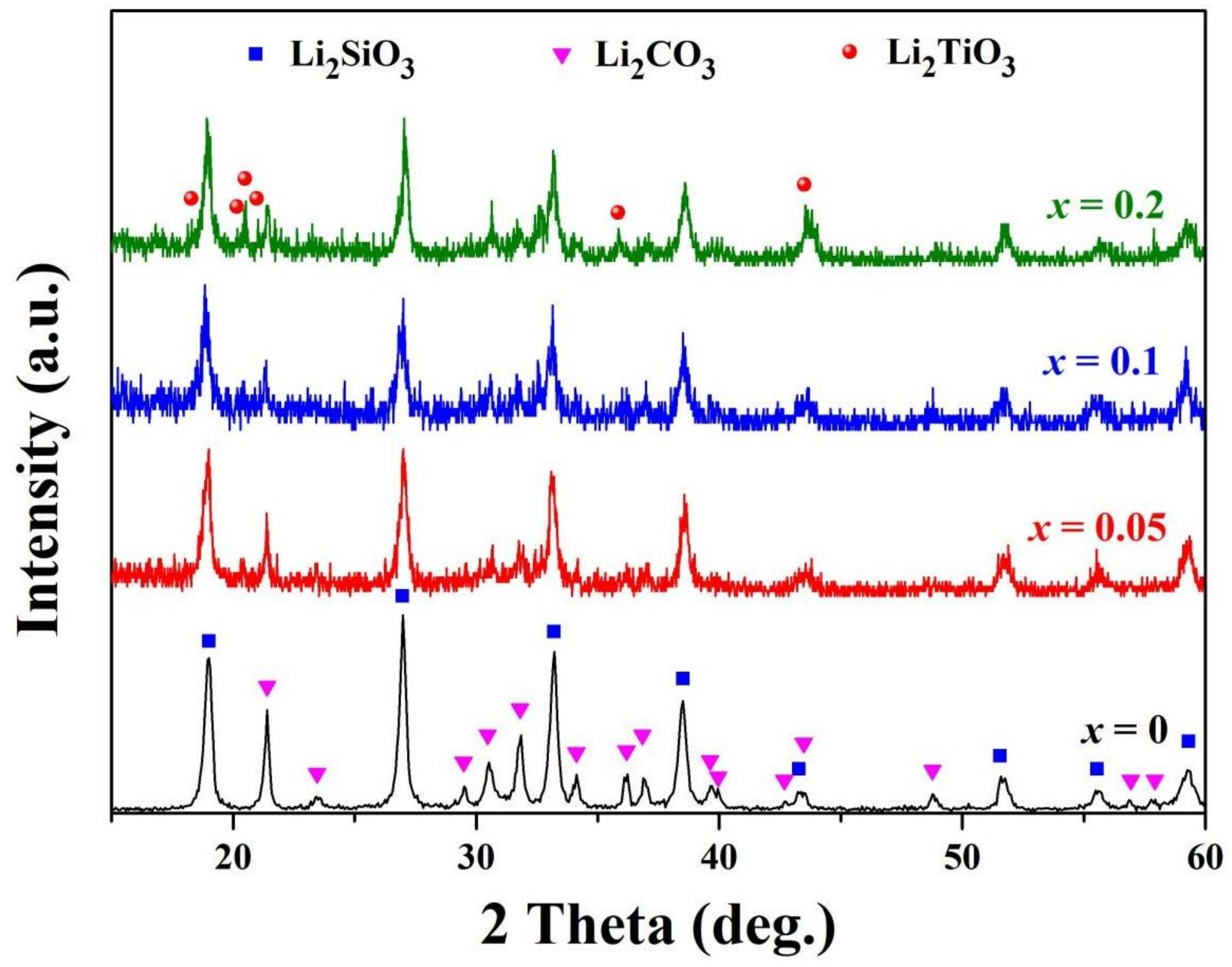

Figure 1

XRD patterns of the precursor powders synthesized by hydrothermal method 

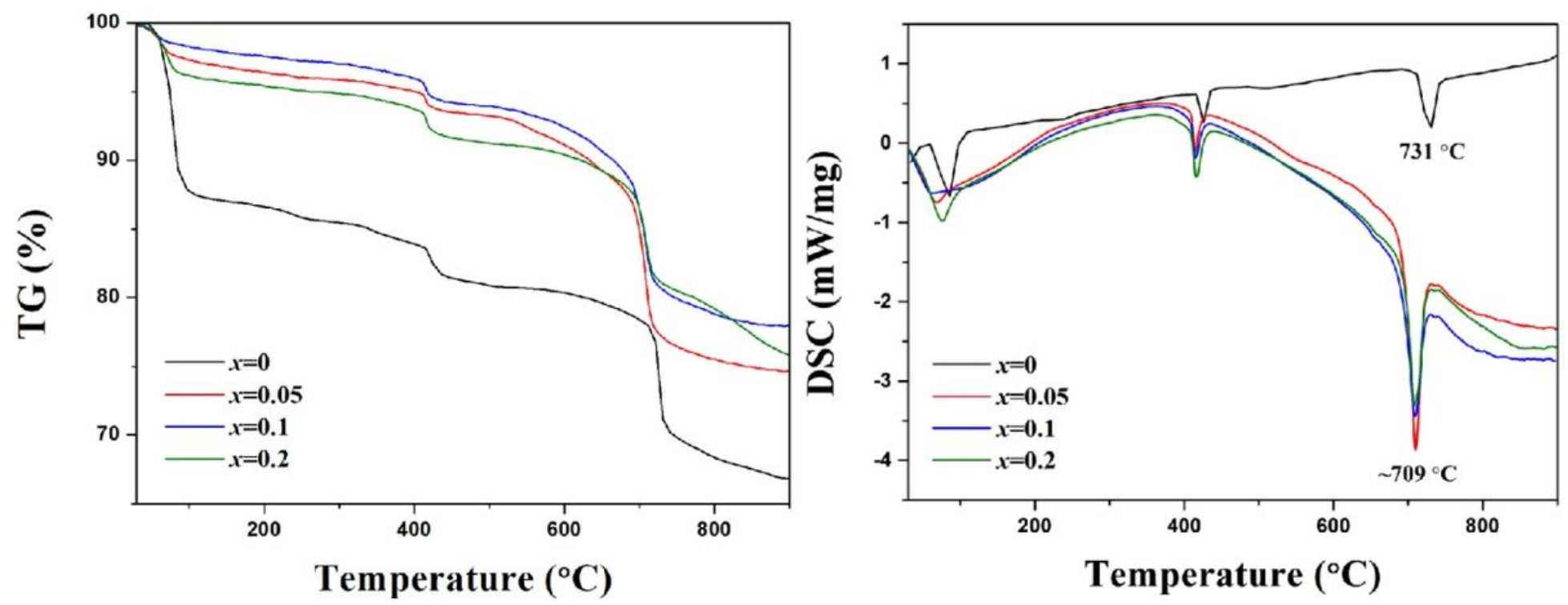

Figure 2

TG/DSC of the precursor powders
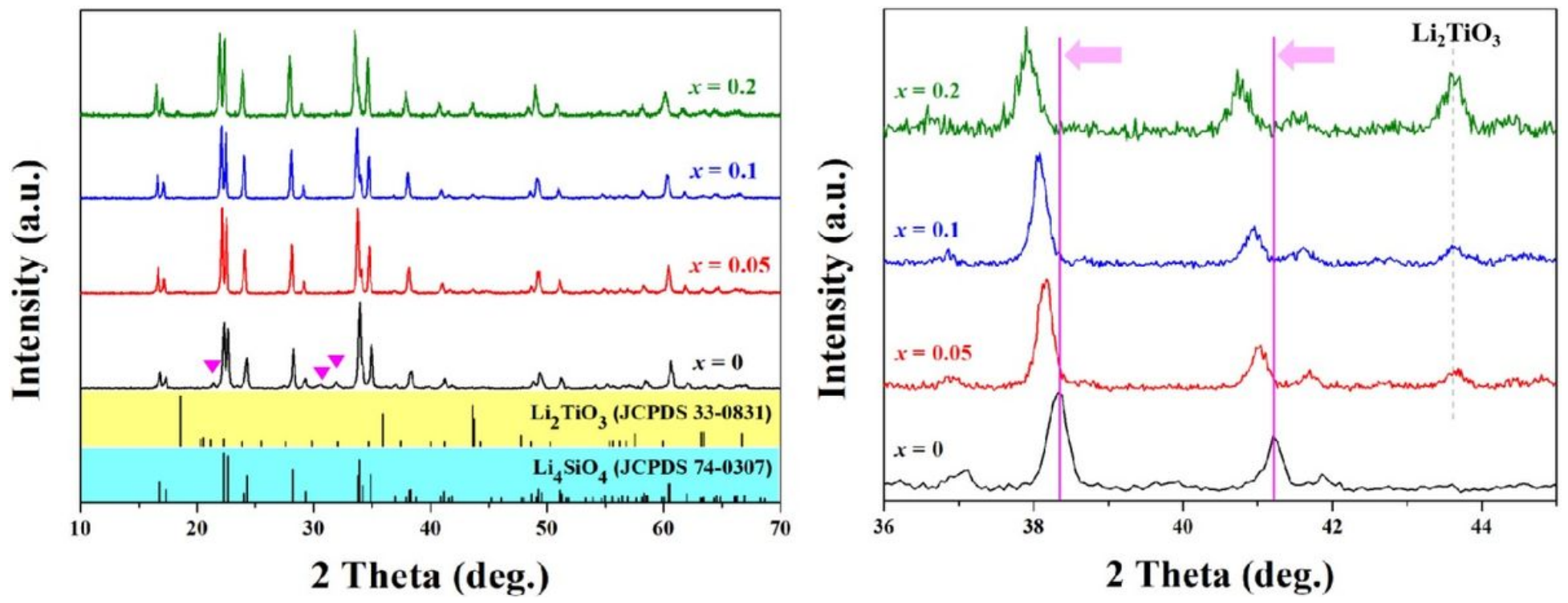

Figure 3

XRD patterns of Li4Si1-xTixO4 

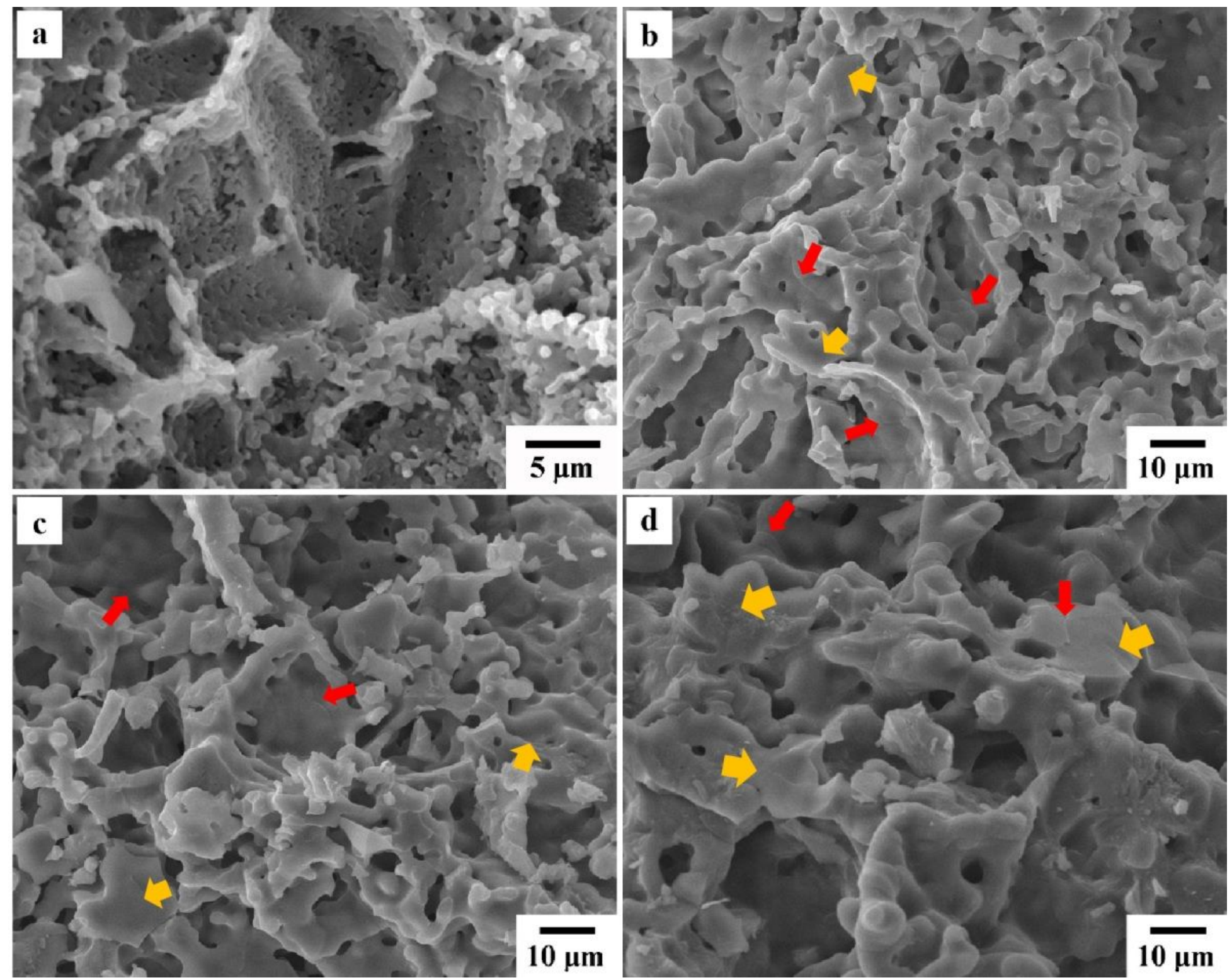

Figure 4

SEM fracture micrographs of Li4Si1-xTixO4 pebbles fabricated via multistage sintering: (a) $x=0$; (b) $\mathrm{x}=0.05 ;$ (c) $\mathrm{x}=0.1 ;$ (d) $\mathrm{x}=0.2$ 

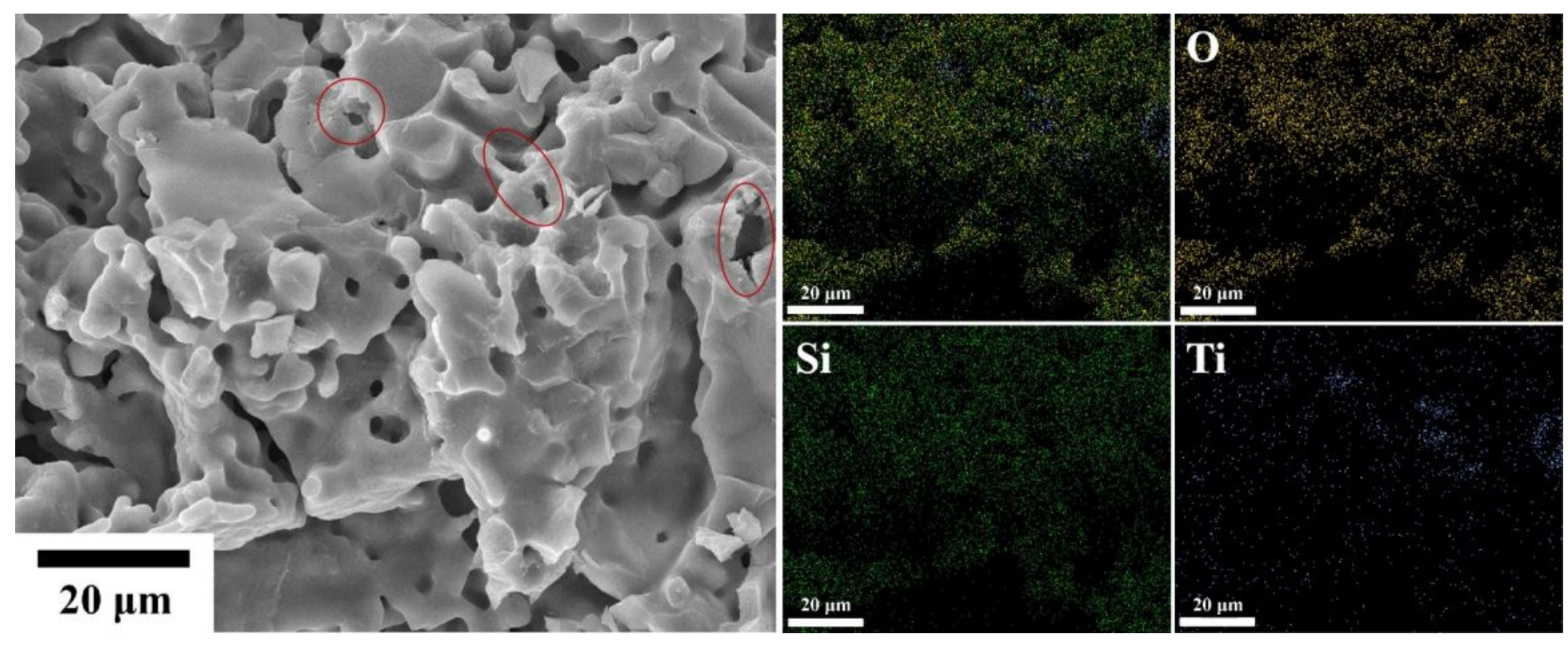

Figure 5

SEM micrographs of Li4Si1-xTixO4 with Ti content $x=0.1$ and corresponding EDS mapping of $\mathrm{Si}, \mathrm{Ti}$ and $\mathrm{O}$ elements

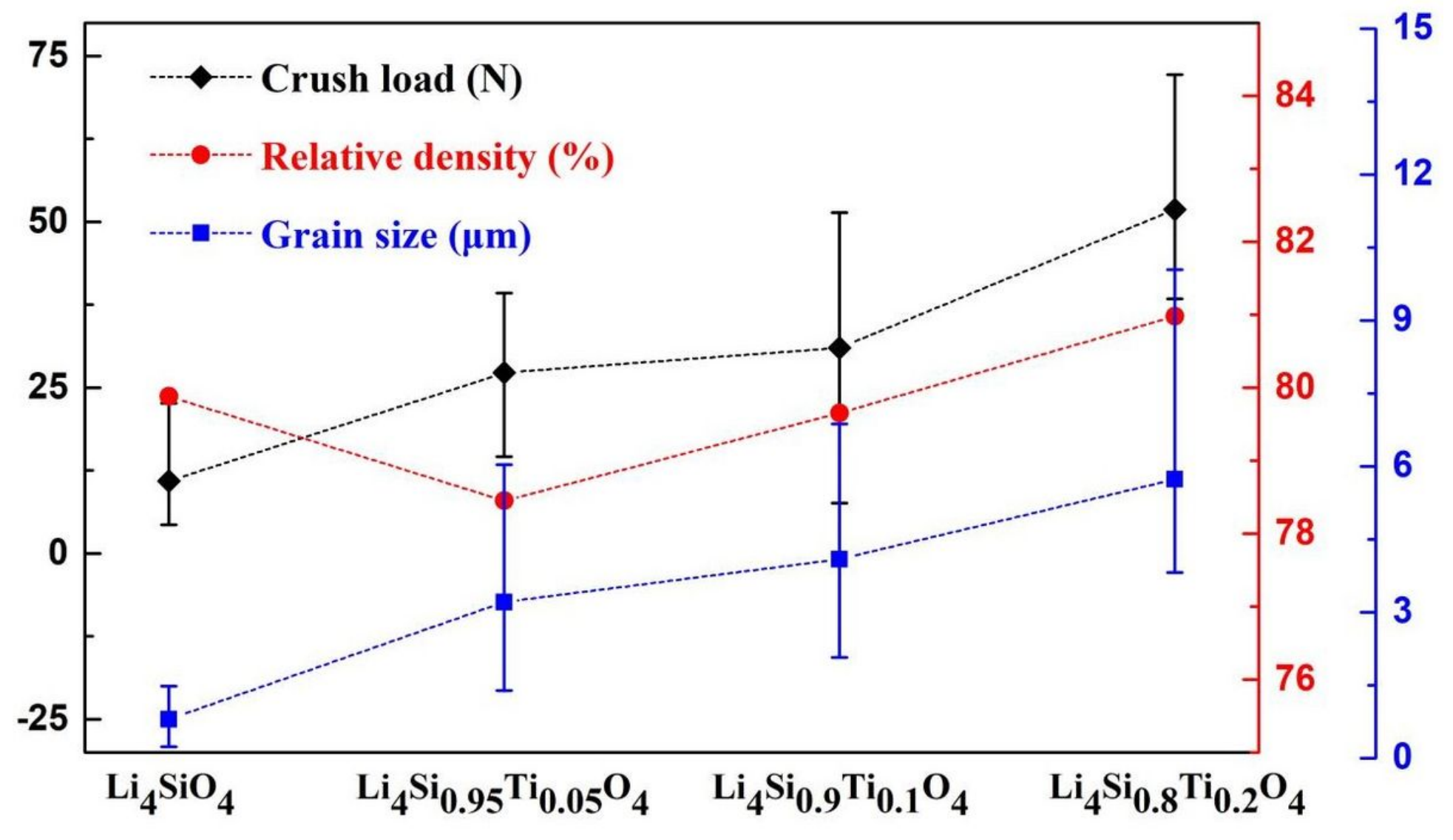

Figure 6

The dependence of crush load, density and grain size on Ti doping content 

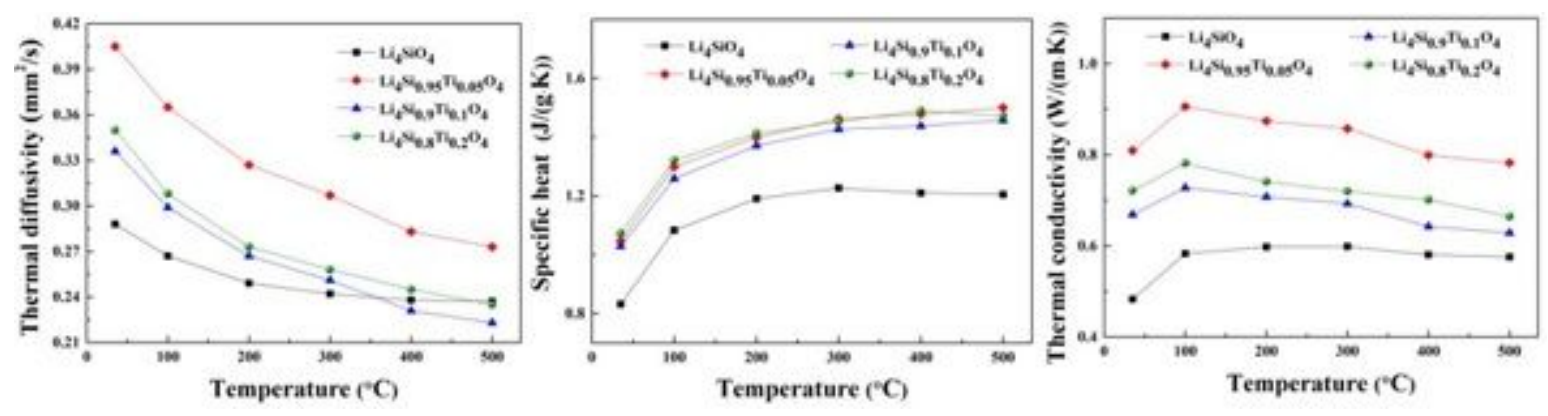

Figure 7

Thermal diffusivity, specific heat and thermal conductivity of Li4Si1-xTixO4 samples $(x=0,0.05,0.1,0.2)$

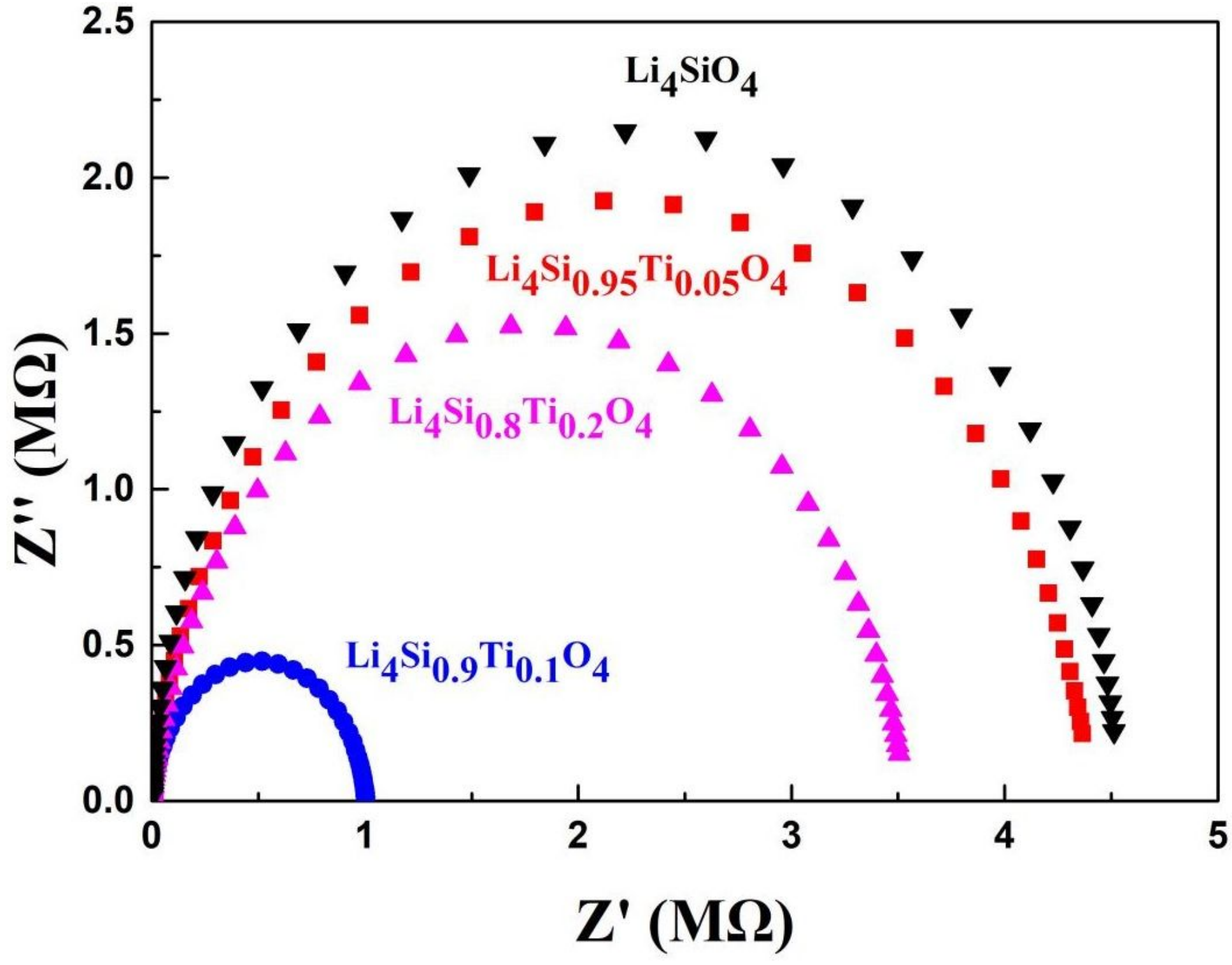

Figure 8

AC impedance spectra for Li4Si1-xTixO4 samples 


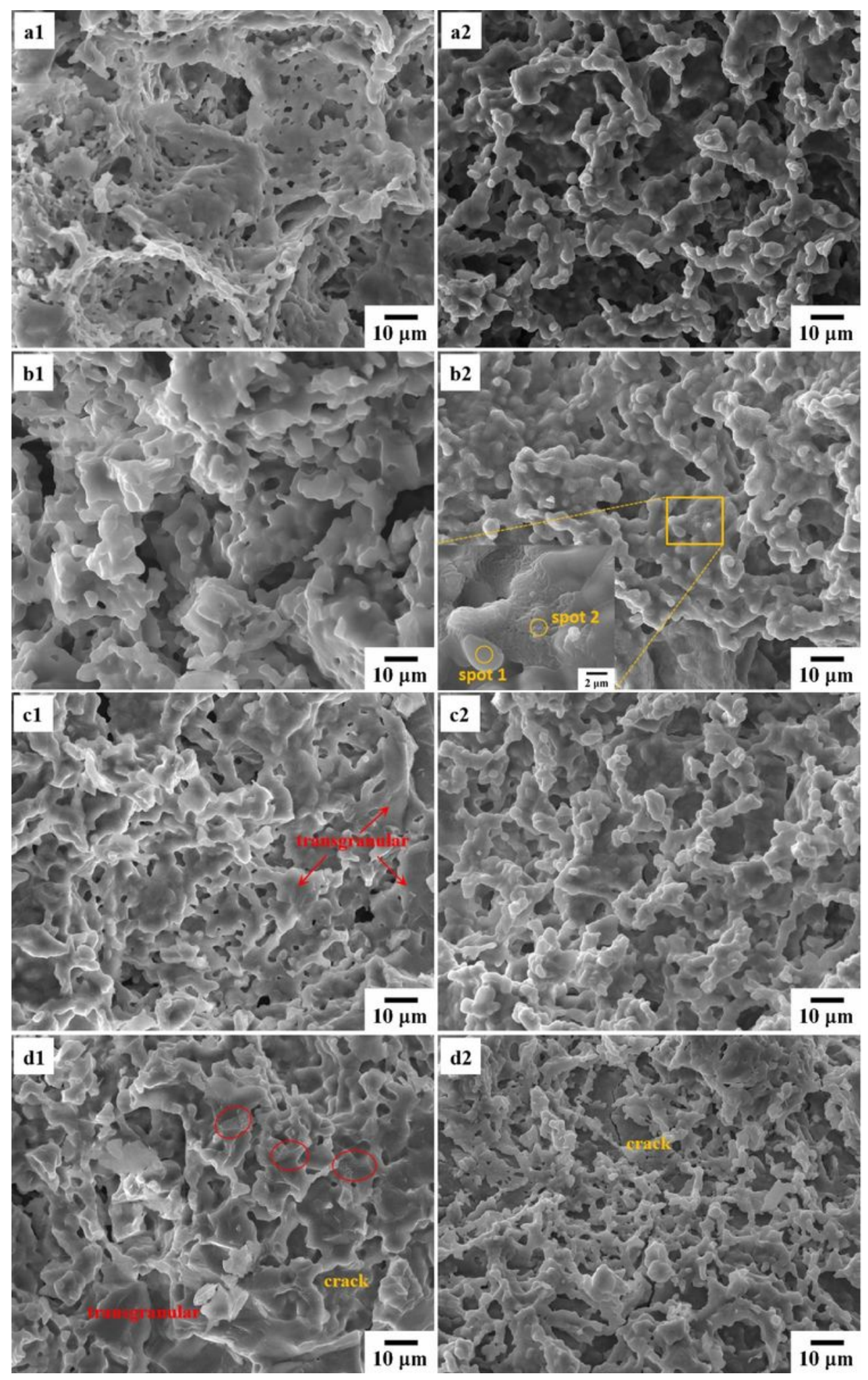

Figure 9

SEM micrographs of Li4SiO4 pebbles after (a) 3 cycles, (b) 6 cycles, (c) 9 cycles, (d) 12 cycles. (1) cross section, (2) surface 


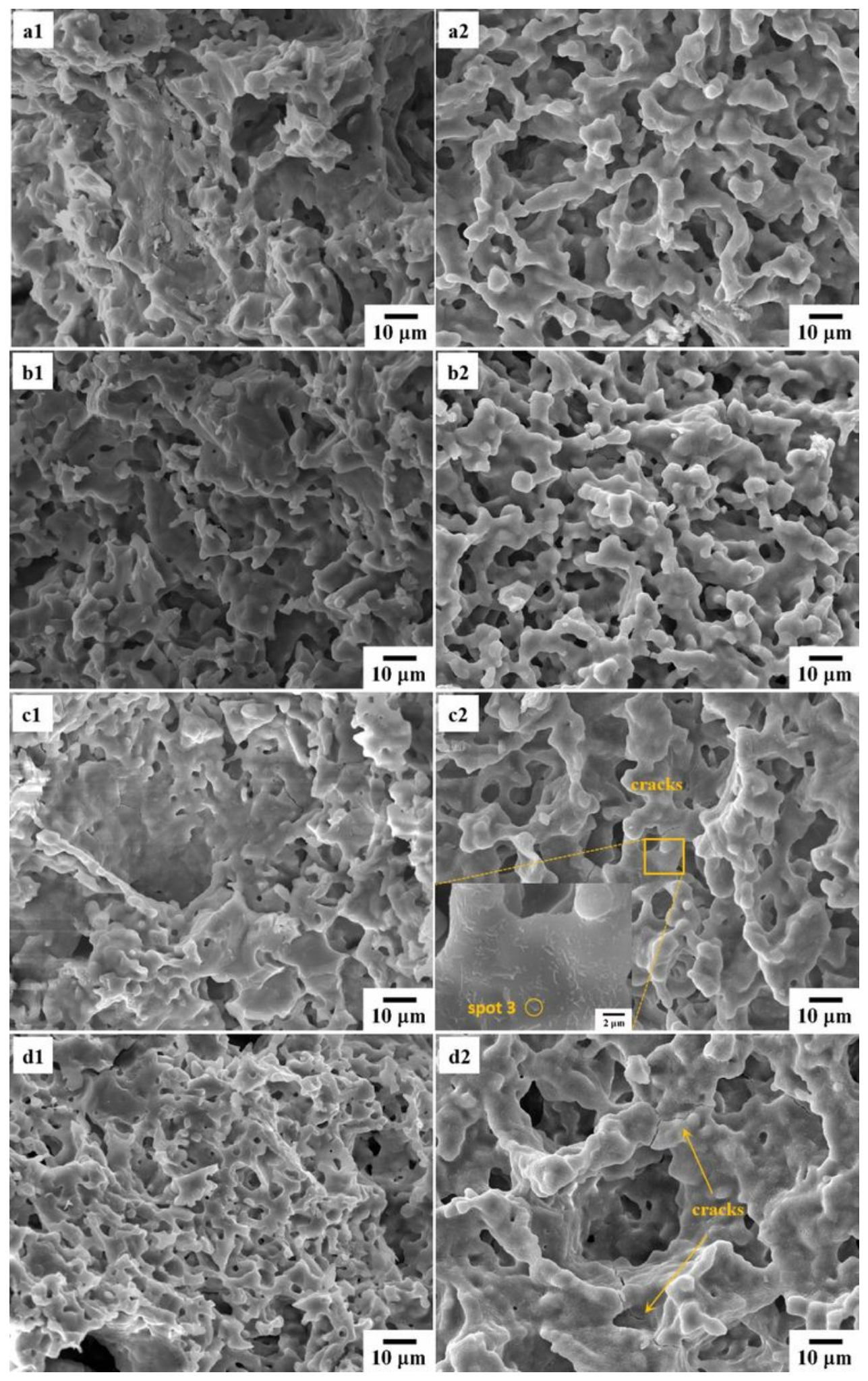

Figure 10

SEM micrographs of Li4Si0.95Ti0.0504 pebbles after (a) 3 cycles, (b) 6 cycles, (c) 9 cycles, (d) 12 cycles. (1) cross section, (2) surface 

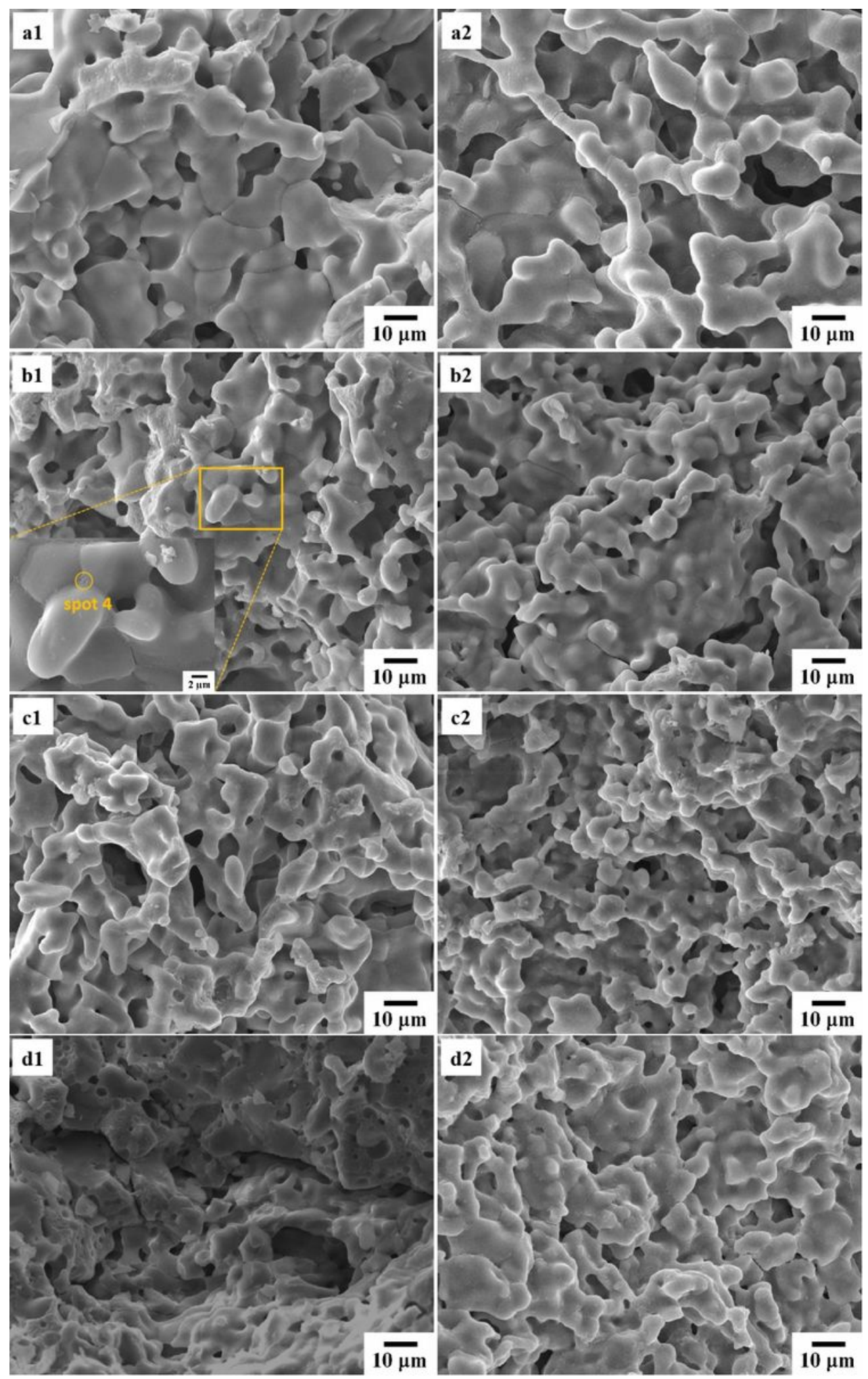

Figure 11

SEM micrographs of Li4Si0.9Ti0.104 pebbles after (a) 3 cycles, (b) 6 cycles, (c) 9 cycles, (d) 12 cycles. (1) cross section, (2) surface 


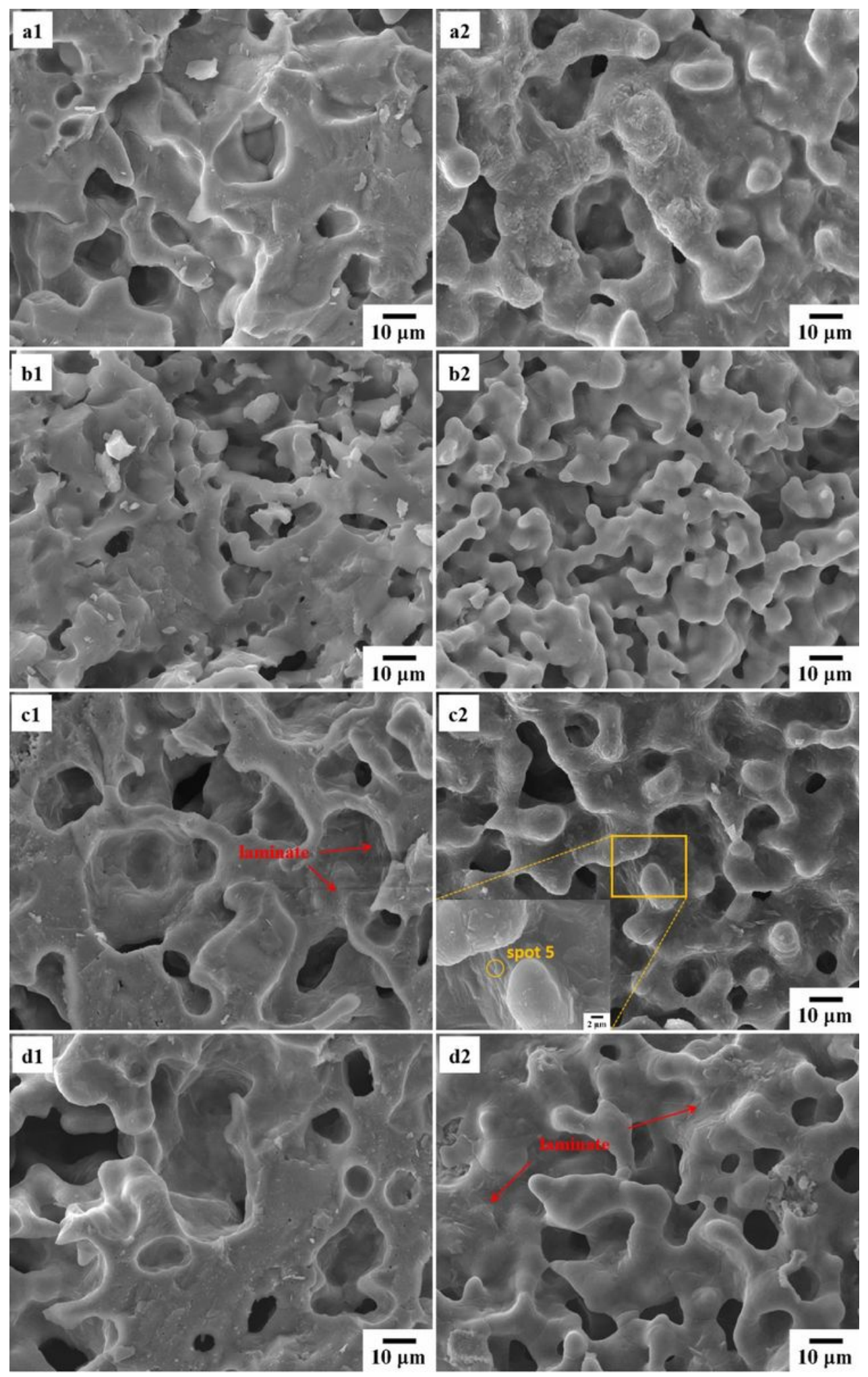

Figure 12

SEM micrographs of Li4Si0.8Ti0.204 pebbles after (a) 3 cycles, (b) 6 cycles, (c) 9 cycles, (d) 12 cycles. (1) cross section, (2) surface 

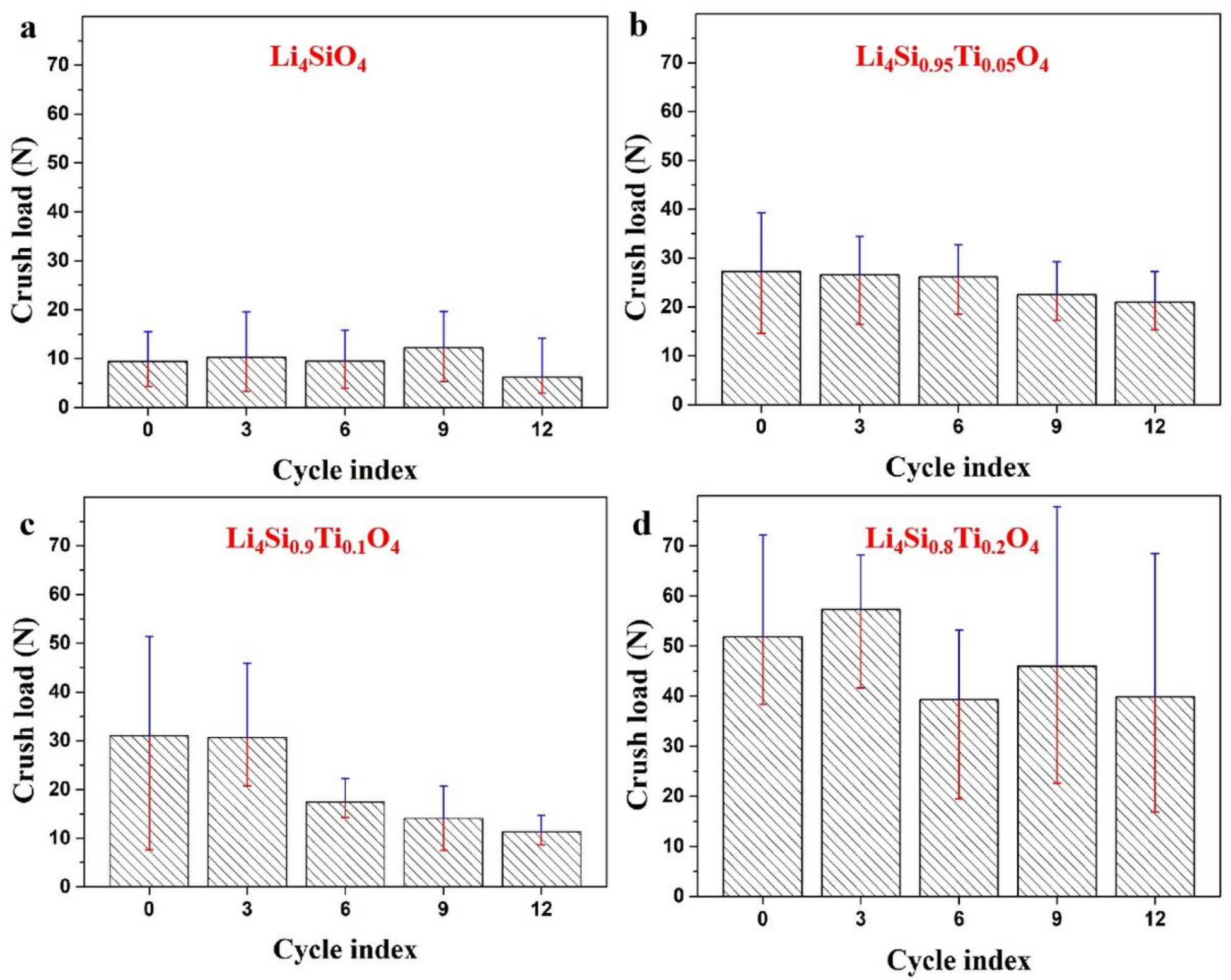

Figure 13

Relationship between the crush load and thermal cycles: (a) Li4SiO4 pebbles, (b) Li4Si0.95Ti0.0504 pebbles, (c) Li4Si0.9Ti0.104 pebbles, (d) Li4Si0.8Ti0.204 pebbles

\section{Supplementary Files}

This is a list of supplementary files associated with this preprint. Click to download.

- SupplementaryMaterial.doc 